\title{
Morphological variation of leaf traits in the Ternstroemia lineata species complex (Ericales: Penthaphylacaceae) in response to geographic and climatic variation
}

\author{
Othón Alcántara-Ayala ${ }^{1,2}{ }^{,}$Ken Oyama $^{3}$, César A Ríos-Muñoz ${ }^{4}$, Gerardo Rivas ${ }^{5}$, Santiago Ramirez-Barahona ${ }^{6}$, \\ Isolda Luna-Vega ${ }^{\text {Corresp. } 2}$ \\ ${ }^{1}$ Posgrado en Ciencias Biológicas, Universidad Nacional Autónoma de México, Mexico City, México \\ 2 Laboratorio de Biogeografía y Sistemática, Departamento de Biología Evolutiva, Facultad de Ciencias, Universidad Nacional Autónoma de México, \\ Mexico City, México \\ 3 Escuela Nacional de Estudios Superiores (ENES), Unidad Morelia, Universidad Nacional Autónoma de México, Morelia, Michoacán, México \\ 4 Coordinación Universitaria para la Sustentabilidad, Universidad Nacional Autónoma de México, Mexico city, México \\ 5 Departamento de Biología Comparada, Facultad de Ciencias, Universidad Nacional Autónoma de México, Mexico City, México \\ 6 Instituto de Biología, Universidad Nacional Autónoma de México, Mexico City, México \\ Corresponding Author: Isolda Luna-Vega \\ Email address: isolda_luna-vega@ciencias.unam.mx
}

Variation in leaf morphology is correlated with environmental variables, such as precipitation, temperature and soil composition. Several studies have pointed out that individual plasticity can largely explain the foliar phenotypic differences observed in populations due to climatic change and have suggested that the environment plays an important role in the evolution of plant species by selecting for phenotypic variation. Thus, the study of foliar morphology in plant populations can help us identify the environmental factors that have potentially influenced the process of species diversification. In this study, we analyzed morphological variation in the leaf traits of the Ternstroemia lineata species complex (Penthaphylacaceae) and its relation to climatic variables across the species distribution area to identify the patterns of morphological differentiation within this species complex. Based on the collected leaves of 270 individuals from 32 populations, we analyzed nine foliar traits using spatial interpolation models and multivariate statistics. A principal component analysis identified three main morphological traits (leaf length and two leaf shape variables) that were used to generate interpolated surface maps to detect discrete areas delimited by zones of rapid change in the values of the morphological traits. We identified a mosaic coarse-grain pattern of geographical distribution in the variation of foliar traits. According to the interpolation maps, we could define nine morphological groups and their geographic distributions. Longer leaves, spatulate leaves and the largest foliar area were located in sites with lower precipitation and higher seasonality of precipitation following a northwest - southeast direction and following significant 
latitudinal and longitudinal gradients. According to the phenogram of the relationships of the nine morphological groups based on morphological similarity, the putative species and subspecies of the $T$. lineata species complex did not show a clear pattern of differentiation. In this study, we found a complex pattern of differentiation with some isolated populations and some other contiguous populations differentiated by different traits. Further genetic and systematic studies are needed to clarify the evolutionary relationships in this species complex. 
2 MORPHOLOGICAL VARIATION OF LEAF TRAITS IN THE TERNSTROEMIA LINEATA

3 SPECIES COMPLEX (ERICALES: PENTHAPHYLACACEAE) IN RESPONSE TO

4 GEOGRAPHIC AND CLIMATIC VARIATION

5

6 Othón Alcántara-Ayala ${ }^{1}, 2$, Ken Oyama ${ }^{3}$, Cesar A. Ríos-Muñoz ${ }^{4}$, Gerardo Rivas ${ }^{5}$, Santiago

7 Ramírez-Barahona ${ }^{6}$ and Isolda Luna-Vega ${ }^{2}$

$8{ }^{1}$ Posgrado en Ciencias Biológicas, Universidad Nacional Autónoma de México, Mexico City, 9 México.

$10{ }^{2}$ Laboratorio de Biogeografía y Sistemática, Departamento de Biología Evolutiva, Facultad de 11 Ciencias, Universidad Nacional Autónoma de México, Mexico City, Mexico.

$12{ }^{3}$ Escuela Nacional de Estudios Superiores (ENES), Unidad Morelia, Universidad Nacional

13 Autónoma de México, Morelia, Michoacán, México.

$14{ }^{4}$ Coordinación Universitaria para la Sustentabilidad, Universidad Nacional Autónoma de

15 México, Mexico City, México.

$16{ }^{5}$ Departamento de Biología Comparada, Facultad de Ciencias, Universidad Nacional Autónoma

17 de México, Mexico City, México.

$18{ }^{6}$ Instituto de Biología, Universidad Nacional Autónoma de México, Mexico City, México.

19 Corresponding author:

20 Isolda Luna-Vega

21 Email address: luna.isolda@gmail.com, isolda_luna-vega@ciencias.unam.mx 


\section{Abstract}

23 Variation in leaf morphology is correlated with environmental variables, such as precipitation,

24 temperature and soil composition. Several studies have pointed out that individual plasticity can 25 largely explain the foliar phenotypic differences observed in populations due to climatic change 26 and have suggested that the environment plays an important role in the evolution of plant species 27 by selecting for phenotypic variation. Thus, the study of foliar morphology in plant populations 28 can help us identify the environmental factors that have potentially influenced the process of 29 species diversification. In this study, we analyzed morphological variation in the leaf traits of the 30 Ternstroemia lineata species complex (Penthaphylacaceae) and its relation to climatic variables 31 across the species distribution area to identify the patterns of morphological differentiation 32 within this species complex. Based on the collected leaves of 270 individuals from 32 populations, we analyzed nine foliar traits using spatial interpolation models and multivariate statistics. A principal component analysis identified three main morphological traits (leaf length and two leaf shape variables) that were used to generate interpolated surface maps to detect discrete areas delimited by zones of rapid change in the values of the morphological traits. We identified a mosaic coarse-grain pattern of geographical distribution in the variation of foliar traits. According to the interpolation maps, we could define nine morphological groups and their geographic distributions. Longer leaves, spatulate leaves and the largest foliar area were located in sites with lower precipitation and higher seasonality of precipitation following a northwest southeast direction and following significant latitudinal and longitudinal gradients. According to the phenogram of the relationships of the nine morphological groups based on morphological similarity, the putative species and subspecies of the $T$. lineata species complex did not show a clear pattern of differentiation. In this study, we found a complex pattern of differentiation with some isolated populations and some other contiguous populations differentiated by different traits. Further genetic and systematic studies are needed to clarify the evolutionary relationships in this species complex.

\section{Introduction}

Intraspecific variation is one of the main sources of information for recognizing evolutionary patterns. Identifying the causes of intraspecific variation is essential to understanding the evolutionary processes that maintain diversity and promote speciation (Futuyma, 1998). In plants, variation occurs in populations of species that are separated in space, encompassing both the genotype and phenotype (Thorpe, 2002). The causes of phenotypic variation among individuals across the geographical distribution range of a species can be broadly divided into current environmental conditions within particular habitats and historical processes and phylogenesis (Thorpe, 1987; Peppe et al., 2011). Plant populations of the same species growing under different environmental conditions respond to different selection pressures, producing genetic and phenotypic divergence between populations (Ramsey, Cairns \& Vaughton, 1994; Fenster \& Stenøien, 2001; Albarrán-Lara et al., 2019). 
61 Plants have developed particular adaptations to the surrounding local climate that allow them to
62 be better fitted to their environment (Chevin et al., 2010; Valladares et al., 2014). The leaf is the

62

63

64

65

66

67

68

69

70

71

72

73

74

75

76

77

78

79

80

81

82

83

84

85

86

87

88

89

90

91

92

93

94

95

96

97

98

99

100 structure in which changes in morphology in response to their environment are more readily acquired by plants (Malhado, 2009a; Yang et al., 2015) because leaves are the organs that perform essential functions, such as photosynthesis and regulation of water content (Givnish, 1979; Wright et al., 2004; Adam \& Ichiro, 2018; Tsukaya, 2018).

Latitudinal and altitudinal variations in leaf size and shape are the result of plastic and adaptive responses of plants to varying environmental conditions, with differences in plant physiological responses also present among populations (Rico-Gray \& Palacios-Ríos, 1996; Niinemets 2001; Uribe-Salas et al., 2008; Frenne et al., 2013; Moles et al., 2014). The correlation between the shape and size of leaves and the surrounding habitat has been interpreted as the result of an evolutionary response of plants to varying environmental conditions (Givnish, 1987; Westoby et al., 2002; Peppe et al., 2011). For instance, leaf size has been shown to decrease with increasing altitude because of the differences in precipitation and with the decrease of soil nutrient content (McDonald et al., 2003; Nicotra, 2011). Additionally, smaller leaves appear to be better adapted to dry environments because the smaller size reduces the hydraulic vulnerability of leaves and makes the plants more tolerant to drought (Scoffoni et al., 2011). Light intensity also plays a key role in the adjustment of leaf size and shape in later stages of development, promoting the expansion of the leaf petiole and inhibiting the growth of the leaf blade (Tsukaya, 2005). Several environmental factors have been shown to play key roles in the evolution of plant species by selecting for phenotypic variation (Pfennig et al. 2010), especially variation related to leaf traits. Thus, the study of foliar morphology in plant populations can help us to identify the environmental factors that have potentially influenced the process of species diversification and phenotypic variability (Ashcroft et al., 2011). The relationships of leaf variation with environmental variables have been focused on the global (Ordoñez, 2009; Yang et al., 2015; Wright et al., 2017), regional (e.g., North America) (Royer et al., 2008) and local scales (e.g., South Australia, Amazonia and Bolivia) (Sokal, Crovello \& Unnasch, 1986; Wright \& Ladiges, 1997; Gregory-Wodzicki, 2000; Malhado, 2009a,2009b; Guerin, Wen \& Lowe, 2012). However, similar patterns are not always identifiable across spatial scales, and in some cases, contrasting trends can be found (Malhado, 2009b; Wright et al., 2017). Studies on how plants respond to environmental variables within regions with a high degree of spatial heterogeneity could be useful for understanding the differential response of plants to climatic gradients (Moeller \& Merilä, 2004). In turn, this knowledge would allow us to know the degree and direction of evolutionary divergence between populations.

The genus Ternstroemia (Penthaphylacaceae, order Ericales) is a group of plants that is poorly understood taxonomically, with the total number of species accepted in the genus varying from 90-110 species (Stevens, 2001; Weitzman, Dressler, Stevens, 2004; Xiang, 2007) to over 160 species (Weitzman, 1995). The genus is distributed from Sri Lanka to SE and E Asia and exists in tropical and subtropical America and in Africa (two species) (Weitzman, Dressler, Stevens, 2004). In Mexico and Central America, Ternstroemia can be found in regions with a great

Peer] reviewing PDF | (2019:03:36010:2:0:NEW 7 Nov 2019) 
101 variety of climates and habitats, ranging from $50 \mathrm{~m}$ to more than $3000 \mathrm{~m}$ (Luna-Vega, Alcántara102 Ayala \& Contreras-Medina, 2004). One of the most widely distributed and common species of 103 Ternstroemia in Mexico is Ternstroemia lineata. In particular, the taxonomic circumscription of $104 T$. lineata has been difficult and thus is considered a species complex composed of several taxa: 105 T. lineata subsp. chalicophila (Loes.) B.M. Barthol., T. dentisepala B.M. Barthol., T. lineata 106 subsp. lineata and T. impressa Lundell. The T. lineata species complex is distributed exclusively

107

108

109

110

111

112

113

114

115

116

117

118

119

120

121

122

123

124

125

126

127

128

129

130

131

132

133

134

135

136

137

138

139

140 in Mesoamerica and is restricted to cloudy conditions at elevations ranging from 1400 to $3140 \mathrm{~m}$ asl in habitats characterized by high precipitation ( $>1000 \mathrm{~mm}$ annually), such as cloud forests and mixed humid forests (Alcántara-Ayala, Luna-Vega, Velázquez, 2002; Luna-Vega, Alcántara-Ayala, Contreras-Medina, 2004). In Mexico and Guatemala, these types of forests occur within a relatively narrow altitudinal zone under humid, temperate climates with continuously foggy conditions. However, different forest patches show local climatic variations that generate heterogeneity in floristic composition. Accordingly, individuals in the T. lineata species complex show great variation in leaf shape and size among populations (Kobuski, 1942; Bartholomew \& McVaugh, 1997; González-Villarreal, 2001).

In this study, we used the Ternstroemia lineata complex as a model to test how climates influence foliar morphology in forest species under environments with high humidity but great geographic heterogeneity. We analyzed how leaf morphology of the Ternstroemia lineata species complex vary in relation to climate variables across its geographic distribution to detect which environmental variables have influenced the leaf morphological differentiation in this species complex. We also tested the degree of leaf morphological differentiation among the putative species and subspecies complex of $T$. lineata.

\section{Materials \& Methods}

Taxon sampling and morphological trait analysis

We collected leaves of 270 individuals (8-10 mature leaves per individual) from 32 populations located throughout the distribution range of the species (Fig. 1). A field permit of scientific collection (Official number SGPA / DGVS / 12770/16) was issued by the Secretaria de Medio Ambiente y Recursos Naturales, of Mexico. Leaf samples were pressed and dried for further measurements in the lab and for herbarium specimens. For each specimen, we measured nine foliar traits: 1. total length including lamina and petiole (TL); 2. lamina length (LL); 3. maximum width of the lamina (MW); 4. petiole length (PL); 5. distance from the base to the maximum width of the lamina (DW); 6. petiole diameter (PD); 7. angle of the lamina apex (ALA); 8. ratio between MW and LL (WLR); and 9. ratio between DW and LL (DWLR) (Fig. 2A). All variables (except ALA) were measured using a Mitutoyo ${ }^{\circledR}$ Vernier caliper $(0.05 \mathrm{~mm}$ resolution $)$ and are recorded in mm. For ALA, we used a Jeppesen PJ-1 Rotating Azimuth Plotter.

\section{Variation of morphological traits}

We performed a principal component analysis (PCA) with the nine traits using the software Statistica (Statsoft, 2009) to group the variables according to their variability and to select those 
141 with the higher values per component to account for most of the morphological variation among

142 individuals (Table 1). With the selected morphological traits (TL, WLR and DWLR),

143 interpolated surface maps were generated in a geographic information system (GIS, ArcMap 10.1

144 ESRI, 2011) using the Geostatistical Analyst extension (Johnston et al., 2001). The traits DWLR

145 and WLR are descriptors of leaf shape. DWLR refers to the degree to which a leaf is spatulate or

146 elliptical, and WLR is indirect evidence of the foliar area (Nautival et al., 1990; Cittadini \& Peri,

147 2006; Singh, 2007), where high values indicate small foliar areas and low values indicate large

148 areas.

149 Finally, the interpolated maps were clipped with a map of the selected hydrographic basins of

150 Mexico (INEGI, INE, CONAGUA, 2007) based on the presence of T. lineata complex records

151 and the altitudinal range obtained from the herbarium specimens and field collections to

152 eliminate the interpolation areas outside the known distribution of the T. lineata complex.

153 We used an empirical Bayesian kriging method, which is based on a semivariogram estimated

154 from the spatial structure of the data (Oliver \& Webster, 1990; Kidd \& Ritchie, 2006; Brito et al.,

155 2008). This kriging method is a geostatistical tool that generates an estimated surface from a set

156 of dispersed points with $\mathrm{Z}$ values. The method is based on statistical models that consider the

157 spatial autocorrelation among data points and provide a measure of precision of the predicted

158 values. We considered the mean error, the square root of the quadratic mean error, the mean

159 standard error, and the square root of the quadratic mean error to evaluate the efficiency of the

160 interpolation (Johnston et al., 2001).

161

162 Geographical areas of morphological homogeneity

163 The three interpolated maps were used to detect discrete areas delimited by zones of rapid

164 change in the values of morphological traits because the variation inside the area is lower than

165 that among the areas. For this method, we used a boundary delineation method with the

166 BoundarySeer software (settings used: crisp boundary type, top 20\% in boundary in threshold(s),

167 thresholds $90 \mathrm{deg}$. vector-to-vector and $30 \mathrm{deg}$. vector-to-line gradient angle). Different

168 boundaries are zones of rapid change, and for detection, wombling methods are used, which

169 estimate the average amount of change in the variable across the space. The locations that have

170 high values of change are referred to as boundaries (BioMedware, 2013).

171 Each map generated by the boundary analysis was vectorized, and all were intersected in a single

172 map using ArcGIS (ESRI, 2011). The resulting polygons represented areas of geographical

173 coincidence of the distribution of the three morphological traits: those polygons where the

174 presence of $T$. lineata complex was not corroborated were eliminated based on the records of

175 biodiversity information systems (REMIB, GBIF, specimens of herbaria). To reduce the number

176 of polygons and group them into homogeneous areas, a cluster analysis was carried out based on

177 the mean values of each of the morphological traits present in each polygon. This analysis was

178 performed using NTSYSpc ver 2.11 (Rohlf, 2000) with a taxonomic distance coefficient and the

179 UPGMA algorithm, and group formation was taken at a value of 0.88 . Finally, the resulting

180 groups were evaluated using discriminant analysis to identify their differences (Table 2). Finally,

Peer] reviewing PDF | (2019:03:36010:2:0:NEW 7 Nov 2019) 
181 the distributions of the values of each of the three variables within each group were represented

182

183

184

185

186

187

188

189

190

191

192

193

194

195

196

197

198

199

200

201

202

203

204

205

206

207

208

209

210

211

212

213

214

215

216

217

218

219

220

using boxplots. Discriminant analysis and boxplot were carried out using SPSS Statistics ver. 19 software (IBM Corp., 2010).

\section{Relationship of morphological traits with climate and geography}

To evaluate the relationship of the morphological traits with the climate across the range of the distribution of this species complex, we used the average values of each polygon, considering 19 bioclimatic variables (Hijmans et al., 2005) (Table 1) and three geographical variables. Values were obtained through a zonal analysis in the GIS. We used the redundancy analysis (RDA) implemented in the package 'vegan' (Oksanen et al., 2018) in R 3.5.1 software ( $R$ Core Team, 2018 ) to determine the combination of environmental and geographical variables that better explain the morphological variation. This analysis was carried out as follows: first, all the bioclimatic variables (BIO01 to BIO19) were included, and an iterative analysis was carried out so that the variables showing high collinearity were eliminated according to their values of variance inflation factor (VIF). Then, to evaluate the effects of climate and geography on leaf trait variation, we performed RDA analysis in three phases: a) an analysis that includes both climatic and geographical variables (RDAfull); b) a partial RDA analysis including only bioclimatic variables without collinearity (pRDA1); and finally, c) a partial RDA analysis including only geographical variables (pRDA2).

We also conducted linear Pearson correlation analyses between the three morphological traits selected after the PCA and the bioclimatic variables without collinearity after an iterative analysis. We included geographic variables such as latitude, longitude and altitude in these linear correlation analyses to detect patterns of leaf morphological variation through latitudinal, longitudinal or altitudinal gradients.

\section{Results}

\section{Leaf morphological variation and interpolation maps}

The principal component analysis of the morphological traits showed that the first three components explained $79.71 \%$ of the accumulated variance $(41.83 \%, 24.32 \%$ and $13.56 \%)$. For the first component, the higher loading values were associated with leaf length (TL and LL) and width (DW and MW), and the second and third components were associated with leaf shape (WLR and DWLR, respectively) (Table 2). The relation among the components showed two sets of variables with maximum correlation associated with the leaf length and width (LL, TL and DW) and the lamina angle and leaf shape (ALA and WLR) (Figs. 2B and 2C).

For the three variables identified as important for each component (TL, WLR and DWLR), we obtained the interpolated surface maps (Figs. 3A-3C). We identified a coarse-grain geographical mosaic distribution in the variation of these foliar traits. The longest leaves occurred in southern Mexico (Sierra Madre del Sur), and the plants with the shortest leaves were mainly located in the southernmost region of the distribution (Sierra Norte y Los Altos de Chiapas and Sierra Madre de Chiapas and Cuchumatanes) and a small area in the western part of the Eje Neovolcánico

Peer) reviewing PDF | (2019:03:36010:2:0:NEW 7 Nov 2019) 
221 (Fig. 3A). Plants with spatulate leaves (higher values of DWLR) were mainly located in the 222 western part of the Eje Neovolcánico and in the southernmost part of the Sierra Madre de 223 Chiapas and Cuchumatanes. Plants with elliptical leaves (lower values of DWLR) were located

224

225

226

227

228

229

230

231

232

233

234

235

236

237

238

239

240

241

242

243

244

245

246

247

248

249

250

251

252

253

254

255

256

257

258

259

mainly in the Sierra Madre del Sur and Sierra del Norte y Altos de Chiapas (Fig. 3B). The regions with plants with the largest foliar area (low values of WLR) were mainly located in the Sierra Madre del Sur, Eje Neovolcánico and Sierra Madre Occidental. The highest WLR values (smaller foliar area) are located in Sierra Madre de Chiapas and Cuchumatanes (Fig. 3C).

Geographical areas of morphological homogeneity and the morphological delimitation of the $T$. lineata species complex

The boundary analyses and the vectorization of the boundary maps produced 228 polygons for the TL map, 395 polygons for the DWLR, and 270 for the WLR (Figs. 3D-3F). The intersection of these three maps and the subsequent elimination of polygons, using only the records of presence of the $T$. lineata complex, produced a single map with 108 polygons (Fig. 4A). The cluster analysis with the average values of the three morphological traits in these 108 polygons generated nine clusters (morphological groups) (Fig. 4B). The discriminant analysis showed significant differences among these nine clusters (Table 3) with the eigenvalues of the first two functions discriminated by $92.7 \%$ with small Wilks' lambda values, which confirms the high variability among these groups. Finally, the percentage error among the groups was minimal $(0.9 \%)$ (Fig. 5A). Figure 5B shows the differences of the three morphological traits among the nine morphological groups.

The nine morphological groups have some correspondence with the species and subspecies of the T. lineata species complex. T. lineata subsp. lineata were formed by the populations of group 1 but also by populations of groups 3, 7 and 9 and some populations of group 4 (in allopatry) and other populations of groups 4 and 5 (in parapatry). Populations of group 2 belong to $T$.

dentisepala, which is distributed in Nayarit state (northwest Mexico), populations of group 6 belong to T. lineata subsp. chalicophila (Chiapas state in southern Mexico) and populations of group 8 belong to T. impressa, which is distributed in Guatemala (Fig. 5C). However, according to the phenogram of the relationships of the nine morphological groups based on morphological similarity, the putative species and subspecies did not show clear patterns of differentiation. For example, the morphological similarity within morphological group 2 ( $T$. dentisepala) was higher and was also higher within the morphological groups of $T$. lineata subsp. lineata (groups 1, 3 and 4). Group 5 was an interesting case because the populations of this group were distributed parapatrically and differentiated from the main cluster of T. lineata subsp. lineata. Populations of the morphological groups 6, 7,8 and 9 were geographically isolated and differentiated in different clusters, and plants of group 8 that were distributed in Guatemala were described as $T$. impressa (Fig. 5C).

Relationship of geography and climate to morphological traits

Peer) reviewing PDF | (2019:03:36010:2:0:NEW 7 Nov 2019) 
260 We selected six bioclimatic variables (BIO01, BIO04, BIO13, BIO14, BIO15 and BIO19) based 261 on an iterative analysis. The results of the full redundancy analysis $(\mathrm{F}=10.037, \mathrm{p}<0.001, \mathrm{~N}=$ 262999 permutations), including geographic and bioclimatic variables, explained $47.79 \%$ of leaf 263 variation $(\mathrm{p}<0.001)$ with two significant axes RD1 and RD2; the first axis explained $83.72 \%$ of 264 the variance, and the second axis explained 13.61\%. The most significant variables for the first 265 axis were precipitation of the driest month (BIO14, $\mathrm{p}<0.001)$, precipitation seasonality (BIO15, $266 \mathrm{p}<0.043)$, precipitation of the coldest quarter $(\mathrm{BIO} 19, \mathrm{p}<0.007)$ and longitude $(\mathrm{p}<0.001)$; for 267 the second axis, the most significant variables were latitude $(\mathrm{p}<0.001)$, precipitation of the 268 wettest month (BIO13, $\mathrm{p}<0.024)$, temperature seasonality (BIO04, $\mathrm{p}<0.014)$ and annual mean 269 temperature $(\mathrm{BIO} 01, \mathrm{p}<0.001)$. The most important morphological variables were total leaf 270 length (TL) and width-length ratio (WLR). The first axis of the full RDA separated those 271 populations mainly located in the south in Sierra del Norte y Los Altos de Chiapas and Sierra 272 Madre de Chiapas and the populations of the Sierra Madre del Sur (in the state of Oaxaca) and 273 the most western area of the Eje Neovólcanico (state of Nayarit) (Fig. 6).

274 The analysis of leaf trait variation indicated that climate had a higher impact than geography.

275 The percentage of the variance explained only by climate was $31.08 \%$, the percentage explained 276 by geography was $13.38 \%$ and the join effect, geography - climate, explained $2.38 \%$.

277 The partial redundancy analysis using climate as control of geography (pRDA1) was significant 278 only in its first axis ( $p<0.001$ ), explaining $87.26 \%$ of the variation, with precipitation of the 279 coldest quarter $(\mathrm{BIO} 19, \mathrm{p}<0.009)$ as the most important variable. The partial redundancy 280 analysis using geography as a control climate (pRDA2) was only significant in its first axis ( $\mathrm{p}<$ 2810.001 ), which explains $99.45 \%$ of the variation, with latitude being the variable of greater 282 importance $(\mathrm{p}<0.001)$ (Fig. 6).

283

284

285

286

287

288

289

290

291

292

293

294

295

296

297

298

299

\section{Relationship between morphological traits and environmental and geographic variables} After the principal component analysis defined TL, WRL and DWLR as the morphological traits that explain most of the variance in the T. lineata species complex and the iterative analysis selected the climatic variables without collinearity, we conducted linear correlations between both groups of variables. Total leaf length (TL) was positively correlated with annual mean temperature $(\mathrm{BIO01})(\mathrm{r}=0.30 ; \mathrm{p}<0.01)$ and precipitation seasonality $(\mathrm{BIO} 15)(\mathrm{r}=0.48 ; \mathrm{p}<$ $0.01)$ and negatively correlated with the precipitation of the driest month (BIO14) $(r=-0.53 ; p<$ $0.01)$, precipitation of the wettest month (BIO13) $(\mathrm{r}=-0.13 ; \mathrm{p}<0.01)$ and precipitation of the coldest quarter (BIO19) $(r=0.45 ; p<0.01)$ (Fig. 7).

The ratio between the maximum width of the lamina (MW) and leaf length (LL) (WRL) as a descriptor of leaf shape was positively correlated with the precipitation of the wettest month (BIO13) $(\mathrm{r}=0.39 ; \mathrm{p}<0.01)$ and precipitation of the driest month (BIO14) $(\mathrm{r}=0.31 ; \mathrm{p}<0.01)$ and was negatively correlated with temperature seasonality (BIO04) $(r=-0.27 ; p<0.01)$ and precipitation seasonality (BIO15) $(\mathrm{r}=-0.37 ; \mathrm{p}<0.01)$ (Fig. 8).

The ratio between the distance from the base to the maximum width of the lamina (DW) and leaf length (LL) (DWLR) was positively correlated with temperature seasonality (BIO04) $(r=0.40 ; p$ 
$300<0.01)$ and precipitation seasonality $(\mathrm{BIO} 15)(\mathrm{r}=0.25 ; \mathrm{p}<0.05)$ and negatively correlated with 301 the precipitation of the wettest month $(\mathrm{BIO} 13)(\mathrm{r}=-0.21 ; \mathrm{p}<0.05)$, precipitation of the driest 302 month $(\mathrm{BIO} 14)(\mathrm{r}=0.32 ; \mathrm{p}<0.01)$ and precipitation of the driest quarter $(\mathrm{r}=-0.41 ; \mathrm{p}<0.01)$ 303 (Fig. 9).

304 Additionally, TL and DWLR were positively correlated with latitude $(\mathrm{r}=0.20 ; \mathrm{p}<0.05 ; \mathrm{r}=$ $3050.22 ; \mathrm{p}<0.05$, respectively) and negatively correlated with longitude $(\mathrm{r}=-0.30 ; \mathrm{p}<0.05 ; \mathrm{r}=$ $3060.24 ; \mathrm{p}<0.05$, respectively), but WLR was negatively correlated with latitude $(\mathrm{r}=-0.53 ; \mathrm{P}<$ $3070.01)$ and positively correlated with longitude $(\mathrm{r}=0.49 ; \mathrm{p}<0.01)$. The three morphological traits 308 were not correlated with altitude (TL: $r=-0.12 ; \mathrm{p}>0.05$; WLR: $r=-0.08 ; \mathrm{p}>0.05$; DWLR: $r=-$ 309 0.14; $\mathrm{p}>0.05)$ (Fig. 10).

310

\section{Discussion}

312 Here, we analyzed leaf morphology in the T. lineata species complex, a group of plants 313 characteristic of the humid forests of Mesoamerica. To detect the role of environmental factors in 314 morphological population differentiation, we studied the general geographic trends in leaf 315 morphology and their relationships with climatic variables such as temperature and precipitation.

316 The populations of the $T$. lineata species complex show great levels of variation in leaf 317 morphology throughout their distribution range. Accordingly, our analyses allowed us to define 318 nine morphologically homogenous groups within the complex and to define their geographic 319 distributions. In general, the pattern we uncovered is a patchy mosaic geographic distribution

320

321

322

323

324

325

326

327

328

329

330

331

332

333

334

335

336

337

338

339 with some groups of populations having a continuous distribution along the central and southern mountains of Mexico (Faja Volcánica Transmexicana, Sierra Madre del Sur). However, we also detected some morphological groups that are distributed parapatrically and others that are isolated at the northern and southern edges of the distribution range of the species complex. Although some groups are consistent with the present-day accepted taxonomic status (Kobuski, 1942; Bartholomew \& McVaugh, 1997), such as the populations identified as T. dentisepala in the north and T. impressa in the south, other groups do not have a clear association with the currently accepted taxonomic circumscription.

Since the 19th century, biogeographers have found that wet tropics harbor plants with larger leaves than those observed in temperate regions, suggesting that small leaves are more frequently found at high latitudes and elevations. Recently, some authors (e.g., Jones, 2014; Michaletz, et al. 2016; Wright, et al. 2017) have attempted to explain the global climatic drivers of leaf size and shape. In general, morphological variation in plants follows changes in environmental variables along latitudinal, longitudinal and altitudinal gradients at different geographic scales (Rico-Gray \& Palacios-Ríos, 1996; Niinemets 2001; Chalcoff, Ezcurra \& Aizen, 2008; UribeSalas et al., 2008; Frenne et al., 2013; Moles et al., 2014). In particular, complex leaf morphology in the $T$. lineata species showed clear patterns of latitudinal and longitudinal variation, but no patterns in morphology were detected across altitude. However, we uncovered strong correlations between leaf morphology and environmental variables. More specifically, leaf area showed a close association with environmental variables, where leaves with lower 
340

341

342

343

344

345

346

347

348

349

350

351

352

353

354

355

356

357

358

359

360

361

362

363

364

365

366

367

368

369

370

371

372

373

374

375

376

377

378

379

surface area were found in regions with higher precipitation throughout the year (i.e., high precipitation during the wettest and driest months), whereas leaves with higher surface area were found in regions with pronounced temperature and precipitation seasonality. Interestingly, this pattern does not follow the general trend observed in plants at a global scale, in which smaller leaves tend to occur in drier sites (Wright et al., 2017).

Variation in leaf shape along environmental gradients has been tied to the response of plant populations to environmental factors (Givinsh, 1987; Malhado et al. 2009a; Malhado et al. 2009b; Werger \& Ellenbroek, 1978). Accordingly, longer leaves in T. lineata were found in regions with higher temperatures and with strong precipitation seasonality, whereas the shortest leaves were found in regions with higher levels of rainfall. In general, longer, narrower and more spatulate leaves were located in regions with lower precipitation and higher precipitation seasonality, following a northwest - southeast direction. However, populations of the $T$. lineata species complex also show differentiation in leaf shape (i.e., narrow spatulate vs elliptical and obovate leaves) within similar mixed cloud forest habitats but still followed significant latitudinal and longitudinal gradients.

The relationship we observed between the length and the surface area of leaves with precipitation seasonality is difficult to explain. Traditionally, a reduction in leaf size has been reported for many species as aridity increases, which represents an adaptive advantage because small leaves have low evapotranspiration (Chalcoff, Ezcurra \& Aizen, 2008). In contrast, our results show that individuals of the $T$. lineata complex with the longest leaves and with the largest leaf areas are found in regions with the lowest extreme rainfall. We believe that the pattern we are observing is due to the habitats in which these plants live. These habitats are characterized by high levels of humidity in the form of cloud, which is more persistent precisely in the driest and coldest periods of the year. In this case, the constant presence of cloud tends to form a thin layer of water on the surface of the leaf, which reduces transpiration and therefore growth (Leigh, 1975, Lightbody, 1985). In addition, this water film reflects sunlight, causing a reduction in photosynthetic activity and therefore affecting the growth rate of the leaves (Lightbody, 1985).

The adaptive value of having more spatulate or elliptical leaves with respect to varying environments is also difficult to explain. Recently, Kidner \& Umbreen (2010) argued that leaf shape is extremely variable between and within species, with great levels of variation in leaf shape among populations and individual plants. The shape of the leaf has been related to the capacity to capture light within distinct habitats and to the regulation of water balance and temperature. In this case, a detailed study of microclimatic variation among populations and analyses of leaf vascular patterns are needed to determine the factors that drive the variation of leaf shape in the $T$. lineata complex.

Variation in leaf traits is due to phenotypic plasticity in response to environmental gradients, and the observed morphological variation is frequently strongly associated with climate (Givnish, 1987; Westoby et al., 2002; Gratani 2014). In this context, the recognition of geographical and morphological groups along the distribution range of the $T$. lineata species complex helped us identify regions where environmental variation mirrored the observed morphological variation 
380

381

382

383

384

385

386

387

388

389

390

391

392

393

394

395

396

397

398

399

400

401

402

403

404

405

406

407

408

409

410

411

412

413

414

415

416

417

418

across populations. There is a clear mosaic-type geographical pattern of variation in some foliar traits, but there is also evidence of correspondence between environmental gradients and leaf size and shape. These results indicate that environmental factors play a relevant role in the observed variation in foliar traits in the $T$. lineata species complex. However, this trait variation is clustered within discrete groups of populations, which are well differentiated geographically. Interestingly, the observed patterns suggest that several groups of populations are morphologically differentiated as a result of geographic isolation. However, there is evidence of significant differentiation in leaf morphology among geographically contiguous populations, suggesting that factors other than climate might influence variation in leaf morphology in Ternstroemia.

\section{Conclusions}

We analyzed the relationship between environmental variables and variation in leaf morphology among populations throughout the distribution range of the T. lineata species complex in Mexico and Guatemala. Showed that the effect of climate varies among populations and than different morphological trends leading to varying patterns of geographic differentiation. The results indicate that converging leaf morphologies can be observed among individuals from different populations, which appears to be a parallel response to similar environmental factors rather than to geographical proximity. Although the climate-morphology association may eventually lead to adaptive evolution in this species complex, the observed patterns should be corroborated with analyses of genetic structure among populations.

The combination of multivariate statistical and geographic analyses of leaf morphology allowed us to establish variability patterns that are a fundamental first step to understanding the process of population differentiation in this group of closely related species. In turn, the integration of genetic data with morphological variation in vegetative and reproductive structures can lead to a better understanding of the reproductive barriers and the processes of species formation in these species. Our research highlights the key role of the environment in molding morphological variation among plant populations at the local and regional scales. Last, a formal taxonomic treatment that includes morphological traits of the leaf, flowers and fruits, together with molecular markers, is needed to evaluate the degree of differentiation among species and subspecies of the T. lineata complex.

\section{Acknowledgements}

This paper is a requirement for O. Alcántara-Ayala in the graduate program of Posgrado en Ciencias Biológicas, Universidad Nacional Autónoma de México (UNAM). OA-A received the support of the CONACYT Grant No. 245683. We acknowledge Andrés Torres-Miranda and Hernán Alvarado-Sizzo for field assistance and their critical suggestions on the final version of this manuscript. We thank to Celia Sanginés, Rito Vega, Antonio Solís, Francisco Maradiaga, Armando Ponce, Mario Véliz, Dagoberto Alavez and Andrés González for field assistance. We 
419 also thank to Ramón Cuevas for the facilities to access the Manantlán Biosphere Reserve. This

420

421

422

423

424

425

426

427

428

429

430

431

432

433

434

435

436

437

438

439

440

441

442

443

444

445

446

447

448

449

450

451

452

453

454

455

456

457

458

study was financially supported by DGAPA-PAPIIT IV201015 and 215914.

\section{References}

Adams WW, Ichiro III. 2018. The leaf: a platform for performing photosynthesis. Springer International Publishing. Cham, Switzerland. DOI 10.1007/978-3-319-93594-2

Albarrán-Lara AL, Petit RJ, Kremer A, Caron H, Dávila P, Gruger PF, Peñaloza-Ramírez JM, Oyama K. 2019. Limited genetic differentiation between two morphologically and ecologically distinct giant-leaved Mexican oaks. Plant Systematics and Evolution 305:89101 DOI 10.1007/s00606-018-1554-8.

Alcántara-Ayala $\mathrm{O}$, Luna-Vega I, Velázquez A. 2002. Altitudinal distribution patterns of Mexican cloud forests based upon preferential characteristic genera. Plant Ecology 161:167-174 DOI 10.1023/A:1020343410735.

Aschcroft MB, French KO, Chisholm LA. 2011. An evaluation of environmental factors affecting species distributions. Ecological Modelling 222:524-531 DOI 0.1016/j.ecolmodel.2010.10.003.

Bartholomew B, McVaugh R. 1997. Identification and typification of Ternstroemia lineata de Candolle (Theaceae). Novon 7:14-16 DOI 10.2307/3392066.

BioMedware. 2013. BoundarySeer: software for the detection and analysis of geographic boundaries. User manual version 1.5. BioMedware, Inc.

Brito JC, Santos X, Pleguezuelos JM, Sillero N. 2008. Inferring evolutionary scenarios with geostatistics and geographical information systems for the viperid snakes Viper alatastei and Viper amonticola. Biological Journal of the Linnean Society 95:790-806 DOI 10.1111/j.1095-8312.2008.01071.x.

Chalcoff VR., Ezcurra C, Aizen MA. 2008. Uncoupled geographical variation between leaves and flowers in a South-Andean Proteaceae. Annals of Botany 102:79-91 DOI 10.1093/aob/mcn057.

Chevin LM, Lande R, Mace GM. 2010. Adaptation, plasticity and extinction in a changing environment: towards a predictive theory. PLoS Biol 8:e1000357 DOI 10.1371/journal.pbio.1000357.

Cittadini, ED, Peri PL. 2006. Estimation of leaf area in sweet cherry using a non-destructive method. Revista de Investigaciones Agropecurias 35:143-150 ISSN : 0325-8718

ESRI. 2011. ArcGIS Desktop: Release 10. Redlands, CA: Environmental Systems Research Institute.

Fenster CB, Stenøien HC. 2001. Clines and ecotypes. In: Robinson R, ed. Plant Sciences Vol. 1. Macmillan Reference USA, 161-163.

Frenne P, Graae BJ, Rodríguez-Sánchez F, Kolb A, Chabrerie O, Decocq G, de Kort H, Schrijver A, Diekmann M, Eriksson O, Gruwez R, Hermy M, Lenoir J, Plue J, Coomes DA, Verheyen. 2013. Latitudinal gradients as natural laboratories to infer species' responses to temperature. Journal of Ecology 101:784-795 DOI 10.1111/1365-2745.12074.

Peer] reviewing PDF | (2019:03:36010:2:0:NEW 7 Nov 2019) 
459 Futuyma DJ. 1998. Evolutionary biology. 3rd ed. Sinauer Associates, Sunderland, MA.

460 Givnish TJ. 1979. On the adaptive significance of leaf form. In: Solbrig OT, Jain S, Johnson GB,

461 Raven PH, eds. Topics in Plant Population Biology. New York: Columbia University

$462 \quad$ Press, 375-407.

463 Givnish TJ. 1987. Comparative studies of leaf form: assessing the relative roles of selective

464

465 pressures and phylogenetic constraints. New Phytologist 106:131-160 DOI

466 10.1111/j.1469-8137.1987.tb04687.x.

González-Villarreal L. 2001. La familia Theaceae en el estado de Jalisco, México. Guadalajara, Jalisco: Universidad de Guadalajara. 41 p. Available at

467

468

469 http://floradejalisco.cucba.udg.mx/12theaceae.pdf (accessed March 22 2018).

Gratani L. 2014. Plant phenotypic plasticity in response to environmental factors. Advances in Botany 2014:1-17 DOI 10.1155/2014/208747.

470

471

472

473

474

475

476

477

478

479

480

481

482

483

484

485

486

487

488

489

490

491

492

493

494

495

496

497

Gregory-Wodzicki KM. 2000. Relationships between leaf morphology and climate, Bolivia: implications for estimating paleoclimate from fossil floras. Paleobiology 26:668-688 DOI10.1666/0094-8373(2000)026<0668:RBLMAC >2.0.CO;2.

Guerin GR, Wen H, Lowe AJ. 2012. Leaf morphology shift linked to climate change. Biology Letters 8:882-886 DOI 10.1098/rsbl.2012.0458.

Hijmans RJ, Cameron SE, Parra JL, Jones PG, Jarvis A. 2005. Very high resolution interpolated climate surfaces for global land areas. The International Journal of Climatology 25:1965-1978 DOI 10.1002/joc.1276.

IBM Corp. Released 2010. IBM SPSS Statistics for Windows, version 19.0. Armonk, NY: IBM Corp.

Instituto Nacional de Estadística Geografía e Informática (INEGI). 2001. Conjunto de datos vectoriales Fisiográficos. Continuo Nacional. Escala 1:1 000 000. Serie I. Disponible en: http://internet.contenidos.inegi.org.mx/contenidos/Productos/prod_serv/contenidos/espan ol/bvinegi/productos/geografia/tematicas/FISIOGRAFIA/702825267575_s.zip

Instituto Nacional de Estadística Geografía e Informática (INEGI), Instituto Nacional de Ecología (INE), Comisión Nacional de Agua (CONAGUA). 2007. Mapa de cuencas hidrográficas de México. Scale 1:250000. Mexico City.

Johnston K, Ver Hoef JM, Krivoruchko K, Lucas N. 2001. Using ArcGIS Geostatistical Analyst. ESRI, Redlands, CA.

Jones HG, 2014. Plants and Microclimate. A Quantitative Approach to Environmental Plant Physiology. 3rd edition. Cambridge University Press. Cambridge, United Kingdom DOI 10.1017/CBO9780511845727.

Kidd DM, Ritchie MG. 2006. Phylogeographic information systems: putting the geography into phylogeography. Journal of Biogeography 33:1851-1865 DOI 10.1111/j.13652699.2006.01574.x.

Kidner C, Umbreen S. 2010. Why is leaf shape so variable?. International Journal of Plant Developmental Biology 4:64-75. 
498

499

500

501

502

503

504

505

506

507

508

509

510

511

512

513

514

515

516

517

518

519

520

521

522

523

524

525

526

527

528

529

530

531

532

533

534

535

536

537

Kobuski CE. 1942. Studies in the Theaceae-XIII. Notes on the Mexican and Central American species of Ternstroemia. Journal of the Arnold Arboretum 23:464-478. DOI 10.5962/bhl.part.18685

Leigh EG.1975. Structure and climate in tropical rain forest. Annual Review of Ecology and Systematics 6: 67-86. DOI 10.1146/annurev.es.06.110175.000435.

Lightbody JP. 1985. Distribution of leaf shapes of Piper sp. in a tropical cloud forest: Evidence for the role of drip-tips. Biotropica 17: 339-342 DOI 10.2307/2388599.

Luna-Vega I, Alcántara-Ayala O, Contreras-Medina R. 2004. Patterns of diversity, endemism and conservation: an example with Mexican species of Ternstroemiaceae Mirb. ex DC. (Tricolpates: Ericales). Biodiversity and Conservation 13:2723-2739 DOI 10.1007/s10531-004-2145-2.

Luna-Vega I, Ochoterena H, 2004. Phylogenetic relationships of the genera of Theaceae based on morphology. Cladistics 20:223-270 DOI: 10.1111/j.1096-0031.2004.00024.x.

Malhado ACM, Whittaker RJ, Malhi Y, Ladle RJ, ter Steege H, Butt N, Aragão LEOC, Quesada CA, Murakami-Araujo A, Phillips OL, Peacock J, López-González G, Baker TR, Anderson LO, Arroyo L, Almeida S, Higuchi N, Killeen TJ, Monteagudo A, Neill DA, Pitman NCA, Prieto A, Salomão RP, Vásquez-M R, Laurance WF, Ramírez H. 2009a. Spatial distribution and functional significance of leaf lamina shape in Amazonian forest trees. Biogeosciences 6:1577-1590 DOI 10.5194/bg-6-1577-2009.

Malhado ACM, Malhi Y, Whittaker RJ, Ladle RJ, ter Steege H, Phillips OL, Butt N, Aragão LEOC, Quesada CA, Araujo-Murakami A, Arroyo L, Peacock J, López-González G, Baker TR, Anderson LO, Almeida S, Higuchi N, Killeen TJ, Monteagudo A, Neill D, Pitman N, Prieto A, Salomão RP, Vásquez-Martínez R, Laurance WF. 2009b. Spatial trends in leaf size of Amazonian rainforest trees. Biogeosciences 6:1563-1576 DOI 10.5194/bg-6-1563-2009.

Marshall JS. 2007. Geomorphology and physiographic provinces. In Bundschuh J, Alvarado GE (Editors) Central America: Geology, Resources and Hazards Vol 1. Taylor \& Francis Group plc. London, UK. 618 p. ISBN-13: 978-0-415-41648-1.

McDonald PG, Fonseca CR, Overton JM, Westoby M. 2003. Leaf-size divergence along rainfall and soil-nutrient gradients: is the method of size reduction common among clades? Functional Ecology 17:50-57 DOI 10.1046/j.1365-2435.2003.00698.x.

Michaletz ST, Weiser MD, McDowell NG, Zhou J, Kaspari M, Helliker BR, Enquist B. 2016. The energetic and carbon economic origins of leaf thermoregulation. Nature Plants 2: 1-9 DOI 10.1038/nplants.2016.129.

Moeller AP, Merilä J. 2004. Analysis and interpretation of long-term studies investigating responses to climate change. Advances in Ecological Research 35:111-130 DOI 10.1016/S0065-2504(04)35006-3.

Moles AT, Perkins SE, Laffan SW, Flores-Moreno H, Awasthy M, Tindall ML, Sack L, Pitman A, Kattge J, Aarssen LW, Anand M, Bahn M, Blonder B, Cavender-Bares J, Hans J. Cornelissen C, Cornwell WC, Díaz S, Dickie JB, Freschet GT, Griffiths JG, Gutierrez AG, 
538

539

540

541

542

543

544

545

546

547

548

549

550

551

552

553

554

555

556

557

558

559

560

561

562

563

564

565

566

567

568

569

570

571

572

573

574

575

576

577

Hemmings FA, Hickler T, Hitchcock TD, Keighery M, Kleyer M, Kurokawa H, Leishman MR, Liu K, Niinemets U, Onipchenko V, Onoda Y, Peñuelas J, Pillar VD, Reich PB, Shiodera S, Siefert A, Sosinski Jr EE, Soudzilovskaia NA, Swaine EK, Swenson NG, van Bodegom PM, Warman L, Weiher E, Wright IJ, Zhang H, Zobel M, Bonser SP. 2014. Which is a better predictor of plant traits: temperature or precipitation? Journal of Vegetation Science 25:1167-1180 DOI 10.1111/jvs.12190.

Nautival BM, Singh PK, Sukla RN, Prakash S, Kumar A. 1990. Correcting leaf area measurement by conventional methods: a new approach for apple (Malus domestica Borkh). Journal of Horticultural Science 65:15-18 DOI 10.1080/00221589.1990.11516022.

Nicotra AB, Leigh A, Boyce CK, Jones CS, Niklas KJ, Royer DL, Tsukaya H. 2011. The evolution and functional significance of leaf shape in the angiosperms. Functional Plant Biology 38:535-552 DOI 10.1071/FP11057.

Niinemets U. 2001. Global-scale climatic controls of leaf dry mass per area, density, and thickness in trees and shrubs. Ecology 82:453-469 DOI 10.1890/00129658(2001)082[0453:GSCCOL]2.0.CO;2.

Oksanen J, Blanchet FG, Friendly M, Kindt R, Legendre P, McGlinn D, Minchin PR, O'Hara RB, Simpson GL, Solymos P, Stevens MHH, Szoecs E, Wagner H. 2018. Vegan: Community Ecology Package. R package. version 2.5-3. https://CRAN.Rproject.org/package $=$ vegan .

Oliver MA, Webster R. 1990. Kriging: A method of interpolation for geographical information systems. International Journal of Geographical Information Systems 4:313-332 DOI 10.1080/02693799008941549.

Ordoñez JC, Van Bodegom PM, Witte JPM, Wright IJ, Reich PB, Aerts R. 2009. A global study of relationships between leaf traits, climate and soil measures of nutrient fertility. Global Ecology and Biogeography 18:137-149. DOI 10.1111/j.1466-8238.2008.00441.x.

Peppe DJ, Royer DL, Cariglino B, Oliver SY, Newman S, Leight E., Enikolopov G, Fernandez-Burgos M, Herrera F, Adams JM, Correa E, Currano ED, Erickson JM, Hinojosa LF, Hoganson JW, Iglesias A, Jaramillo CA, Johnson KR, Jordan GJ, Kraft NJB, Lovelock EC, Lusk CH, Niinemets U, Peñuelas J, Rapson G, Wing SL, Wright, IJ. 2011. Sensitivity of leaf size and shape to climate: global patterns and paleoclimatic applications. New Phytologist 190:724-739. DOI 10.1111/j.1469-8137.2010.03615.x.

Pfennig DW, Wund MA, Snell-Rood EC, Cruickshank T, Schlichting CD, Moczek AP. 2010. Phenotypic plasticity impacts on diversification and speciation. Trends in Ecology and Evolution 25:459-467 DOI 10.1016/j.tree.2010.05.006.

Ramsey MW, Cairns SC, Vaughton GV. 1994. Geographic variation in morphological and reproductive characters of coastal and tableland populations of Blandfordia grandiflora (Liliaceae). Plant Systematics and Evolution 192:215-230 DOI 10.1007/BF00986253.

R Core Team. 2018. R: A language and environment for statistical computing. R Foundation for Statistical Computing, Vienna, Austria. URL https:/www.R-project.org/. 
578 Rico-Gray V, Palacios-Ríos M. 1996. Leaf area variation in Rhizophora mangle L.

579

580

581

582

583

584

585

586

587

588

589

590

591

592

593

594

595

596

597

598

599

600

601

602

603

604

605

606

607

608

609

610

611

612

613

614

615

616

(Rhizophoraceae). Global Ecology and Biogeography Letters 5:30-35 DOI $10.2307 / 2997468$.

Rohlf FJ. 2000. NTSYSpc: Numerical taxonomy and multivariate analysis system. Version $2.11 \mathrm{x}$. Applied Biostatistics Inc, Nueva York.

Royer DL, McElwain JC, Adams JM, Wilf P. 2008. Sensitivity of leaf size and shape to climate within Acer rubrum and Quercus kelloggii. New Phytologist 179: 808-817 DOI $10.1111 / \mathrm{j} .1469$.

Scoffoni C, Rawls M, McKown A, Cochard H, Sack L. 2011. Decline of leaf hydraulic conductance with dehydration: relationship to leaf size and venation architecture. Plant Physiology 156:832-843 DOI 10.1104/pp.111.173856.

Singh A. 2007. Approximation of leaf area by using leaf dimensions in guava. I International Guava Symposium. Acta Horticulturae 735:321-324 DOI 10.17660/ActaHortic.2007.735.44.

Sokal RR, Crovello TJ, Unnasch RS. 1986. Geographic variation of vegetative characters of Populus deltoides. Systematic Botany 11:419-432 DOI 10.2307/2419078

Statsoft Inc. 2009. Statistica 7.0. StatSoft Inc., Tulsa, USA.

Stevens PF. 2001 onwards. Angiosperm phylogeny website. Version 14, July 2017 [and more or less continuously updated since]. Available at http://www.mobot.org/MOBOT/research/APweb/ (accessed 21 November 2018).

Thorpe RS. 1987. Geographic variation: a synthesis of cause, data, pattern and congruence in relation to subspecies, multivariate analysis and phylogenesis. Bolletino Di Zoologia 54:3-11 DOI10.1080/11250008709355549.

Thorpe RS. 2002. Geographic variation. In: Pagel M, ed. Encyclopedia of Evolution. Oxford University Press, 430-435. DOI 10.1093/acref/9780195122008.001.0001.

Tsukaya H. 2005. Leaf shape: genetic controls and environmental factors. The International Journal of Developmental Biology 49:547-555 DOI 10.1387/ijdb.041921ht.

Tsukaya H. 2018. A consideration of leaf shape evolution in the context of the primary function of the leaf as a photosynthetic organ. In: Adams WW, Terashima I, eds. The leaf: a platform for performing photosynthesis. Springer. Cham, Switzerland, 1-26. DOI 10.1007/978-3-319-93594-2_1.

Uribe-Salas D, Sáenz-Romero C, González-Rodríguez A, Téllez-Valdez O, Oyama K. 2008. Foliar morphological variation in the white oak Quercus rugosa Née (Fagaceae) along a latitudinal gradient in Mexico: potential implications for management and conservation. Forest Ecology and Management 256:2121-2126 DOI 10.1016/j.foreco.2008.08.002. Valladares F, Matesanz S, Guilhaumon F, Araújo MB, Balaguer L, Benito-Garzón M, Cornwel W, Gianoli E, van Kleunen M, Naya DE, Nicotra AB, Poorter H, Zavala MA. 2014. The effects of phenotypic plasticity and local adaptation on forecasts of species range shifts under climate change. Ecology Letters 17:1351-1364 DOI 10.1111/ele.12348.

Peer) reviewing PDF | (2019:03:36010:2:0:NEW 7 Nov 2019) 
617 Weitzman A.L. 1995. Diversity ofTheaceae and Bonnetiaceae in the Montane Neotropics. In:

618

619

620

621

622

623

624

625

626

627

628

629

630

631

632

633

634

635

636

637

638

639

640

641

642

643

644

645

646

647

648

649

650 Churchill SP, Balslev H, Forero E, Luteyn JL. eds. Biodiversity and Conservation of Neotropical Montane Forests. New York: The New York Botanical Carden, 365-375.

Weitzman AL, Dressler S, Stevens PF. 2004. Ternstroemiaceae. In: Kubitzki K. eds. Flowering Plants · Dicotyledons. The Families and Genera of Vascular Plants, vol 6. Springer, Berlin, Heidelberg.

Werger MJA, Ellenbroek GA. 1978. Leaf size and leaf consistence of a riverine forest formation along a climatic gradient. Oecologia 34:297-308 DOI 10.1007/BF00344908.

Westoby M, Falster DS, Moles AT, Vesk PA, Wright IJ. 2002. Plant ecological strategies: some leading dimensions of variation between species. Annual Review of Ecology and Systematics 33:125-159. DOI 10.1146/annurev.ecolsys.33.010802.150452.

Wright IJ, Ladiges PY. 1997. Geographic variation in Eucalyptus diversifolia (Myrtaceae) and the recognition of new subspecies E. diversifolia subsp. hesperia and E. diversifolia subsp. megacarpa. Australian Systematic Botany 10:651-680 DOI 10.1071/SB96019.

Wright IJ, Reich PB, Westoby M, Ackerly DD, Baruch Z, Bongers F, Cavender-Bares J, Chapin T, Cornelissen JHC, Diemer M, Flexas J, Garnier E, Groom PK, Gulias J, Hikosaka K, Lamont BB, Lee T, Lee W, Lusk C, Midgley JJ, Navas ML, Niinemets U, Oleksyn J, Osada N, Poorter H, Poot P, Prior L, Pyankov VI, Roumet C, Thomas SC, Tjoelker MG, Veneklaas EJ, Villar R. 2004. The worldwide leaf economics spectrum. Nature 428:821827 DOI 10.1038/nature02403.

Wright IJ, Dong N, Maire V, Prentice IC, Westoby M, Díaz S, Gallagher RV, Jacobs BF, Kooyman R, Law EA, Leishman MR, Niinemets Ü, Reich PB, Sack L, Villar R, Wang H, Wilf P. 2017. Global climatic drivers of leaf size. Science 357:1-5 DOI 10.1126/science.aal4760.

Xiang HP. 2007. Ternstroemia. In Zhengyi W, Raven PH, Deyuan H. eds. Flora of China, Volume 12: Hippocastanaceae through Theaceae. Science Press \& Missouri Botanical Garden. St. Louis, Missouri, USA. 475 pages ISBN: 1930723792.

Yang J, Spicer RA, Spicer TEV, Arens NC, Jacques FMB, Su T, Kennedy EM, Herman AB, Steart DC, Srivastava G, Mehrotra RC, Valdes PJ, Mehrotra NC, Zhou Z-K, Lai JS, 2015. Leaf form-climate relationships on the global stage: an ensemble of characters. Global Ecology and Biogeography 24:1113-1125 DOI 10.1111/geb.12334. 


\section{Table 1 (on next page)}

List of climatic variables using of the redundancy analysis.

Climatic variables used in the redundancy analysis. (** Climatic variables with VIF $>10$ ) 
1 Table 1. Climatic variables used in the redundancy analysis. (** Climatic variables with VIF>10)

\begin{tabular}{ll}
\hline Abbreviations & Climatic variable names \\
\hline BIO1** & Annual Mean Temperature \\
BIO2 & $\begin{array}{l}\text { Mean Diurnal Range (Mean of monthly (max temp - min } \\
\text { temp) }\end{array}$ \\
BIO3 & Isothermality (BIO2/BIO7) $(* 100)$ \\
BIO4** & Temperature Seasonality (standard deviation *100) \\
BIO5 & Max Temperature of the Warmest Month \\
BIO6 & Min Temperature of the Coldest Month \\
BIO7 & Temperature Annual Range (BIO5-BIO6) \\
BIO8 & Mean Temperature of the Wettest Quarter \\
BIO9 & Mean Temperature of the Driest Quarter \\
BIO10 & Mean Temperature of the Warmest Quarter \\
BIO11 & Mean Temperature of the Coldest Quarter \\
BIO12 & Annual Precipitation \\
BIO13** & Precipitation of the Wettest Month \\
BIO14** & Precipitation of the Driest Month \\
BIO15** & Precipitation Seasonality (Coefficient of Variation) \\
BIO16 & Precipitation of the Wettest Quarter \\
BIO17 & Precipitation of the Driest Quarter \\
BIO18 & Precipitation of the Warmest Quarter \\
BIO19** & Precipitation of the Coldest Quarter \\
\hline
\end{tabular}

2

3

4 


\section{Table 2 (on next page)}

Principal Component Analysis of nine morphological variables of the $T$. lineata species complex.

Principal Component Analysis of nine morphological variables of the $T$. lineata species complex. Variables: 1) total length of leaf (includes lamina and petiole, TL); 2) lamina length $(L L)$; 3) maximum width of the lamina (MW); 4) petiole length (PL); 5) distance from the base to the maximum width of the lamina (DW); 6) petiole diameter (PD); 7) angle of the lamina apex (ALA); 8) ratio between MW and LL (WLR); and 9) ratio between DW and LL (DWLR). 
1 Table 2. Principal Component Analysis of nine morphological variables of the T. lineata species 2 complex. Variables: 1) total length of leaf (includes lamina and petiole, TL); 2) lamina length 3 (LL); 3) maximum width of the lamina (MW); 4) petiole length (PL); 5) distance from the base 4 to the maximum width of the lamina (DW); 6) petiole diameter (PD); 7) angle of the lamina apex 5 (ALA); 8) ratio between MW and LL (WLR); and 9) ratio between DW and LL (DWLR).

6

7

8

9

10

11

12

13

14

15

16

17

18

19

20

\begin{tabular}{cccccc}
\hline Contributions & $\mathrm{C}_{1}$ & $\mathrm{C}_{2}$ & $\mathrm{C}_{3}$ & $\mathrm{C}_{4}$ & $\mathrm{C}_{5}$ \\
& & & & & \\
\hline PL & 0.041737 & 0.000777 & 0.161636 & 0.726383 & 0.016466 \\
PD & 0.054816 & 0.186583 & 0.009767 & 0.068551 & 0.258501 \\
MW & 0.189874 & 0.083223 & 0.015169 & 0.012927 & 0.000201 \\
TL & 0.244426 & 0.029179 & 0.002038 & 0.001309 & 0.011538 \\
LL & 0.239342 & 0.032236 & 0.000070 & 0.018755 & 0.016813 \\
DW & 0.228145 & 0.028064 & 0.052958 & 0.000150 & 0.001161 \\
WLR & 0.000166 & 0.379410 & 0.026536 & 0.000723 & 0.038457 \\
DWLR & 0.000956 & 0.000000 & 0.663112 & 0.148503 & 0.081381 \\
ALA & 0.000538 & 0.260529 & 0.068714 & 0.022698 & 0.575481 \\
\% & & & & & \\
ACUMULATED & 41.83 & 66.15 & 79.71 & 94.04 & 99.59 \\
VARIANCE & & & & & \\
\hline
\end{tabular}




\section{Table 3 (on next page)}

The discriminant analysis showing significant differences among the nine clusters

(A) Eigenvalues of the functions show that the first two functions discriminate by $92.7 \%$. (B) Wilks Lambda values and Chi-square, $\mathrm{p}=0.05$. 
1 Table 3. A) Eigenvalues of the functions show that the first two functions discriminate by $92.7 \%$.

2 B) Wilks Lambda values and Chi-square, $p=0.05$.

3

A) Eigenvalue

\begin{tabular}{lrrrr}
\hline Function & Eigenvalue & $\begin{array}{c}\text { \% of } \\
\text { variance }\end{array}$ & $\begin{array}{c}\text { Cumulative } \\
\%\end{array}$ & $\begin{array}{l}\text { Canonical } \\
\text { correlation }\end{array}$ \\
\hline 1 & $10.251^{\mathrm{a}}$ & 60.3 & 60.3 & .955 \\
2 & $5.506^{\mathrm{a}}$ & 32.4 & 92.7 & .920 \\
3 & $1.249^{\mathrm{a}}$ & 7.3 & 100.0 & .745 \\
\hline
\end{tabular}

${ }^{a}$ We used the three first canonical discriminant functions in the analysis.

B) Wilks' Lambda

\begin{tabular}{lrrrr}
\hline $\begin{array}{l}\text { Test of } \\
\text { functions }\end{array}$ & $\begin{array}{c}\text { Wilks' } \\
\text { Lambda }\end{array}$ & \multicolumn{1}{c}{ Chi-square } & \multicolumn{1}{c}{ df } & \multicolumn{1}{c}{ Sig } \\
\hline 1 to 3 & 0.006 & 515.478 & 24 & .000 \\
2 to 3 & 0.068 & 271.010 & 14 & .000 \\
3 & 0.445 & 81.858 & 6 & .000 \\
\hline
\end{tabular}


Figure 1

Location of the sampled populations throughout the $T$. lineata complex distribution range

Distribution of the Ternstroemia lineata species complex in the main mountain systems of Mexico (sensu INEGI, 2001) and Guatemala (sensu Marshall, 2007).

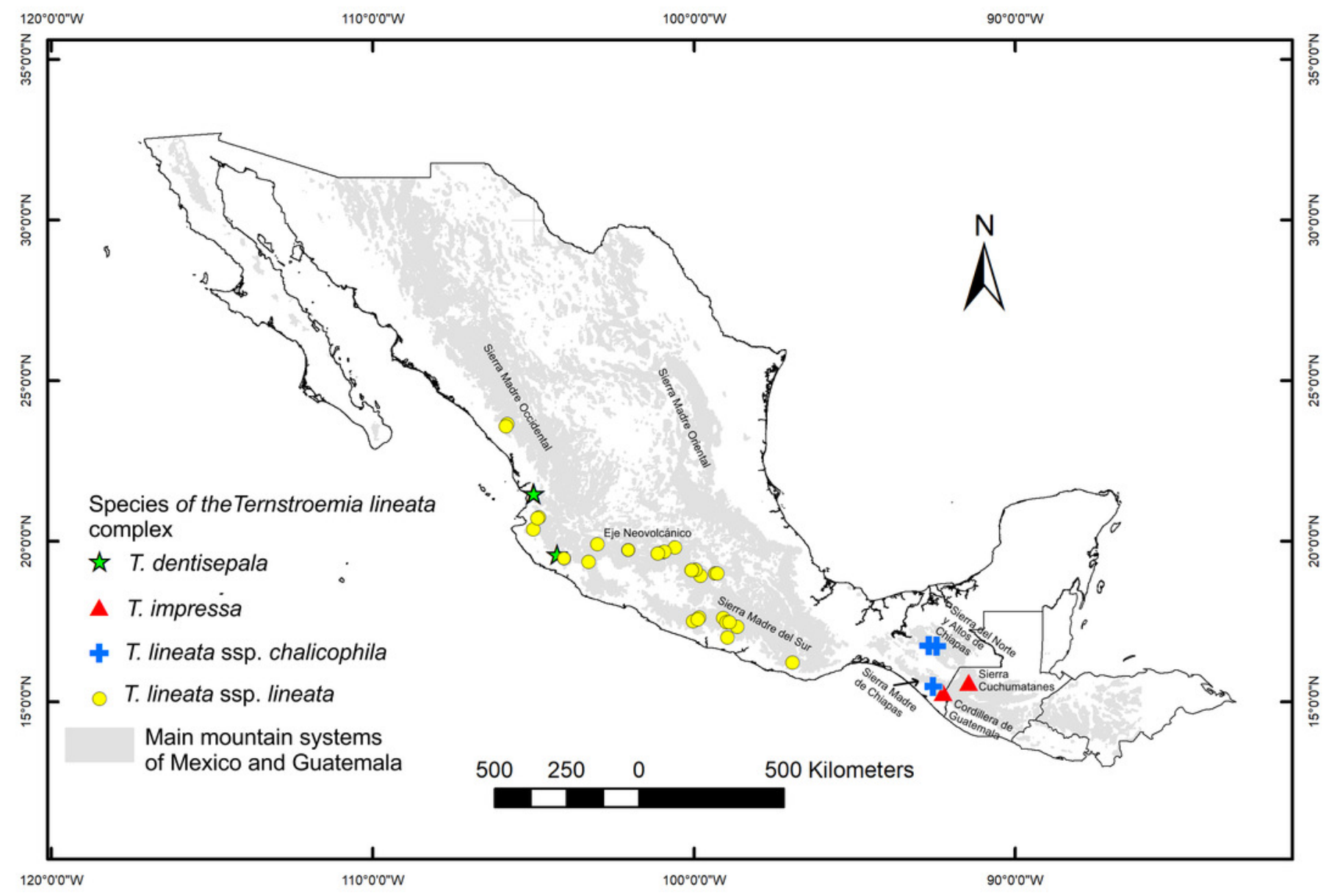




\section{Figure 2}

Nine foliar traits and Principal Component Analysis (PCA) of this variables

Foliar measurements and PCA analysis of the morphological variables. A) The nine foliar traits measured in each individual: 1) total leaf length (including lamina and petiole, $T L$ ); 2) lamina length (LL); 3) maximum width of the lamina (MW); 4) petiole length (PL); 5) distance from the base to the maximum width of the lamina (DW); 6) petiole diameter (PD); 7) angle of the lamina apex (ALA); 8) ratio between MW and LL (WLR); 9) ratio between DW and LL (DWLR). B-C) We plotted the PCA values of the morphological variables: first component vs. second component (B) and second component vs. third component $(C)$ we show two sets of variables with maximum correlation: LL-TL-DW and ALA-WLR. The number ( $B$ and $C$ ) corresponds to species of $T$. lineata complex, 1. $T$. lineta ssp. chalicopila, 2. T. dentisepala, 3. T. lineata ssp. lineata and 4. T. impressa. 


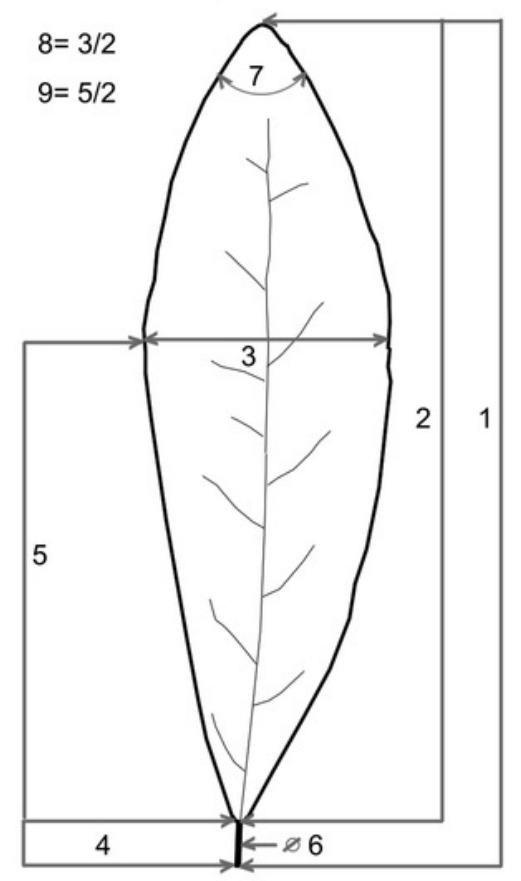

A
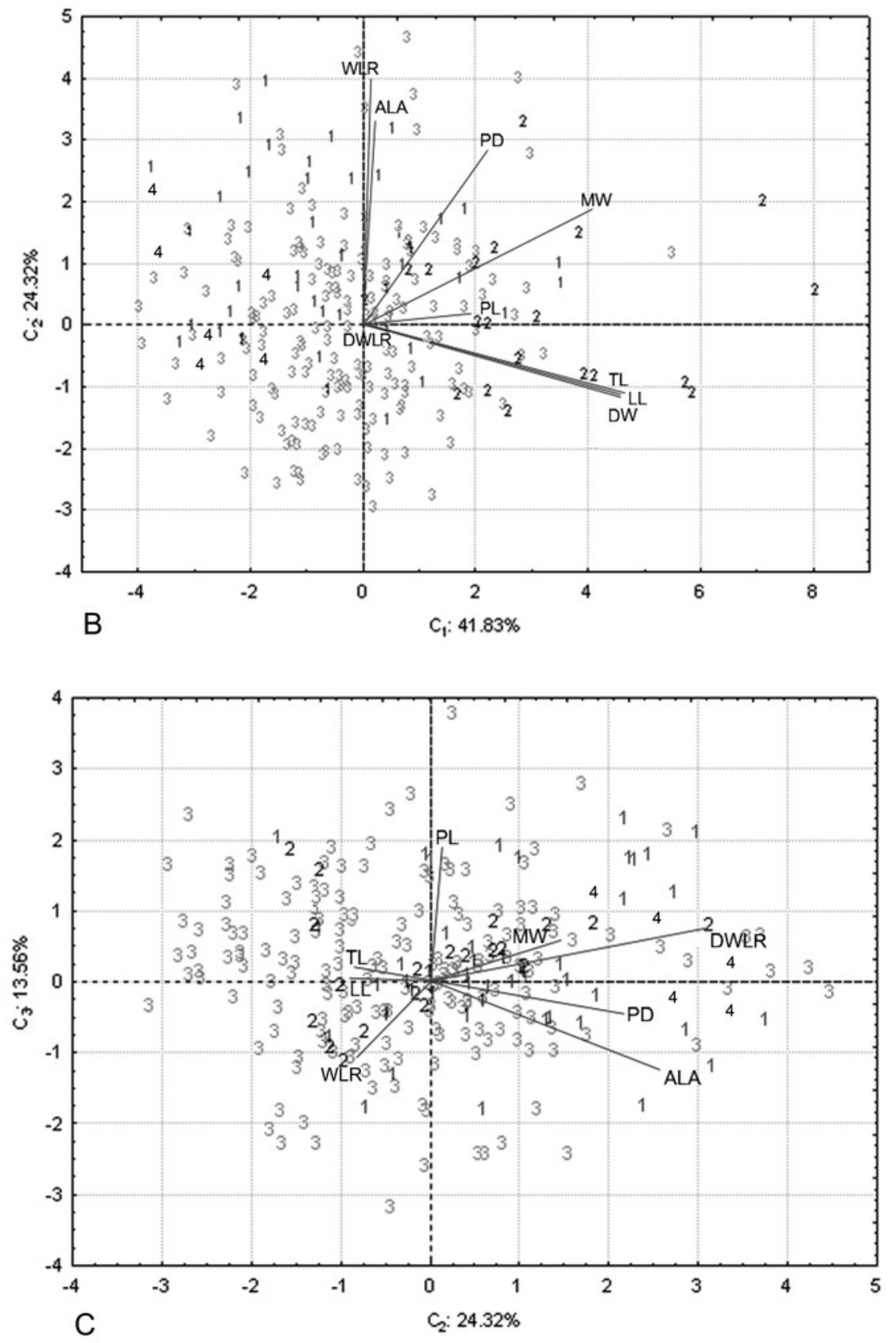


\section{Figure 3}

The interpolated surface maps

Interpolation maps for $(A)$ total leaf length $(T L),(B)$ ratio between the distance from the base to the maximum width of the lamina (DW) and leaf length (LL) (DWLR) and (C) ratio between maximum width of the lamina (MW) and leaf length (LL) (WLR). (D-E) Boundary detection analyses based on the interpolated surface maps of the three leaf traits (TL, DWLR, WLR, respectively). 

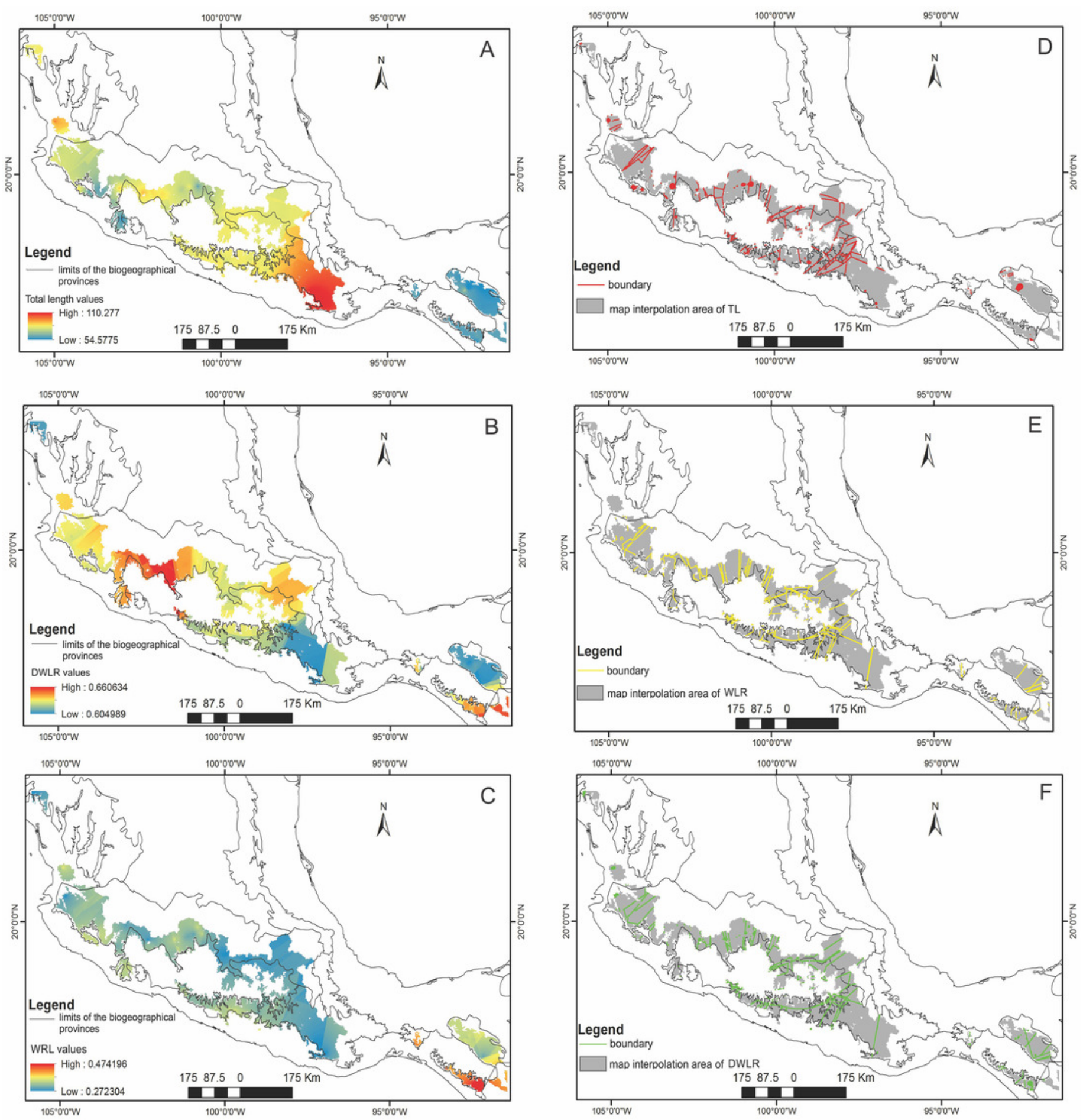


\section{Figure 4}

The intersection of three maps and phenogram resulted from a cluster analysis of the 108 polygons

(A) Map with polygons generated by the intersection of the three maps of morphological variables (see Figure 3D-F) after the boundary analysis and the vectorization of the boundary maps using only the records of presence of the $T$. lineata complex (green dots). (B) Phenogram resulted from a cluster analysis of the 108 polygons. 

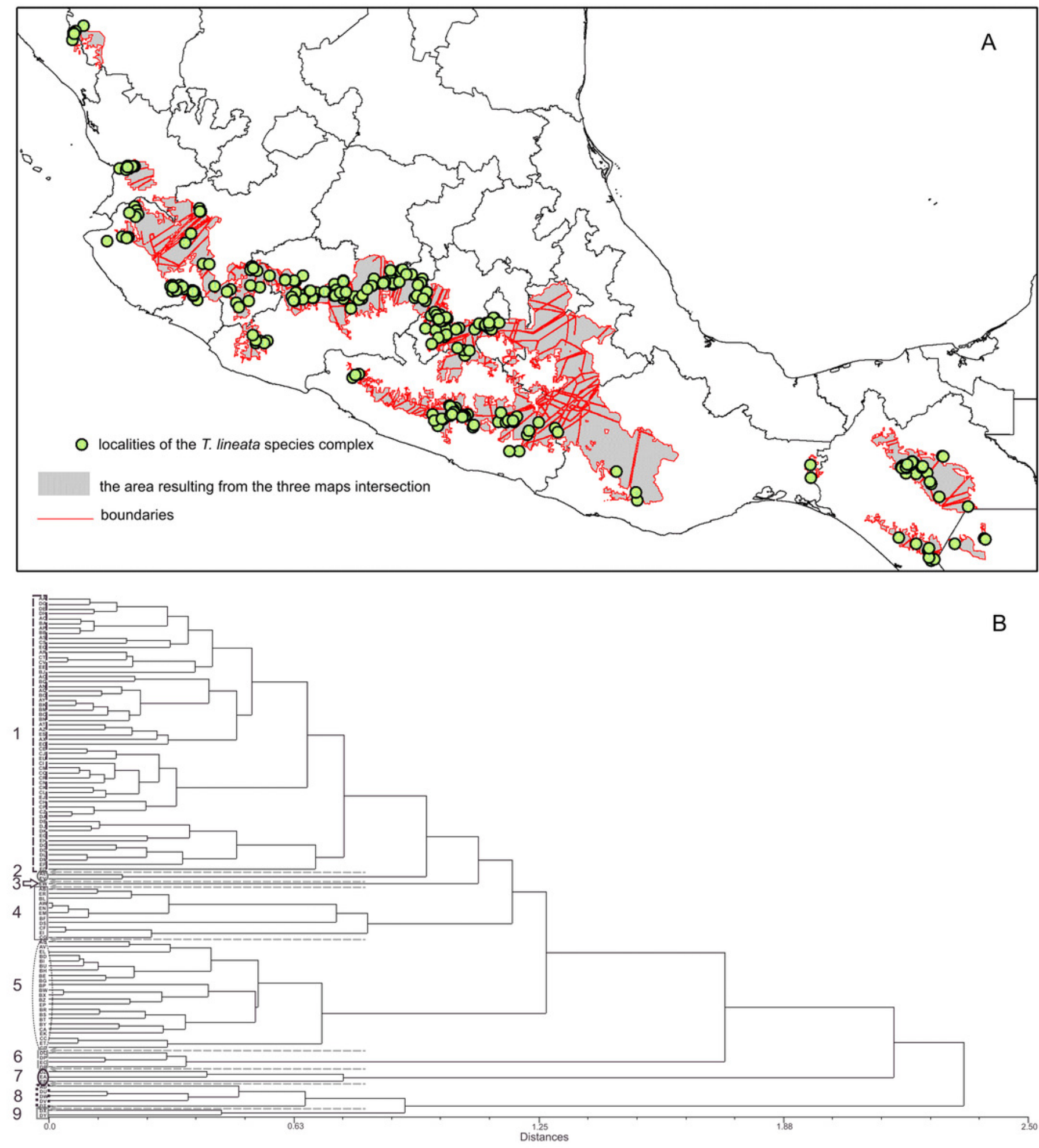


\section{Figure 5}

Biplot discriminant analysis, boxplot of the differences of the three morphological traits among the nine morphological groups and distribution map of this nine morphological groups.

(A) Canonical discriminant charts where the integrity of the nine groups was tested; (B) boxplot of the nine morphological groups; (C) Distribution map of the nine morphological groups (with a typical leaf sample). 

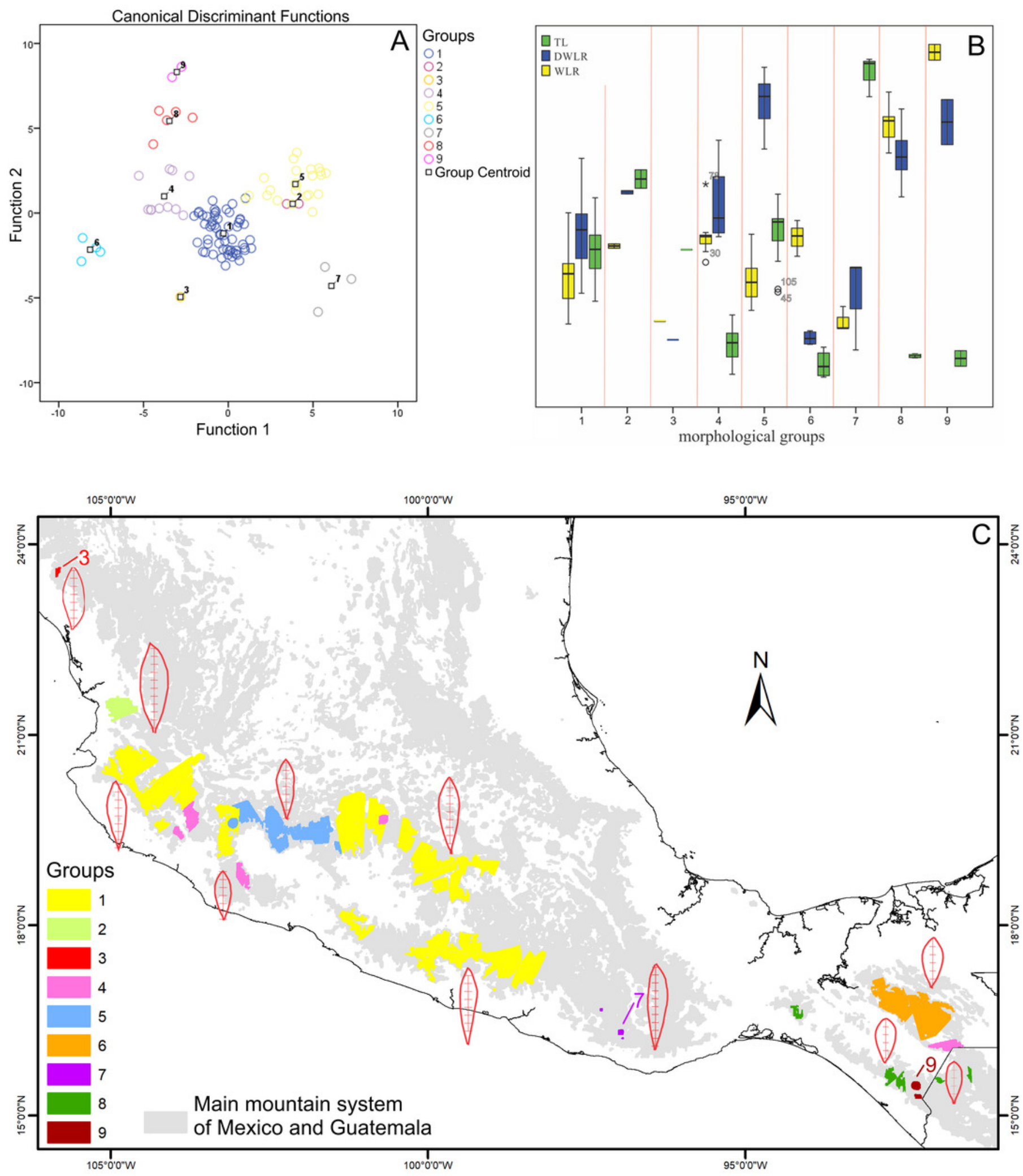
Figure 6

Graph of the redundancy analysis that includes both climatic and geographical variables (RDAfull).

Graph of full redundancy analysis (Full RDA) showing the relationship between response variables (morphological characters) and explanatory variables (bioclimatic and geographic variables).

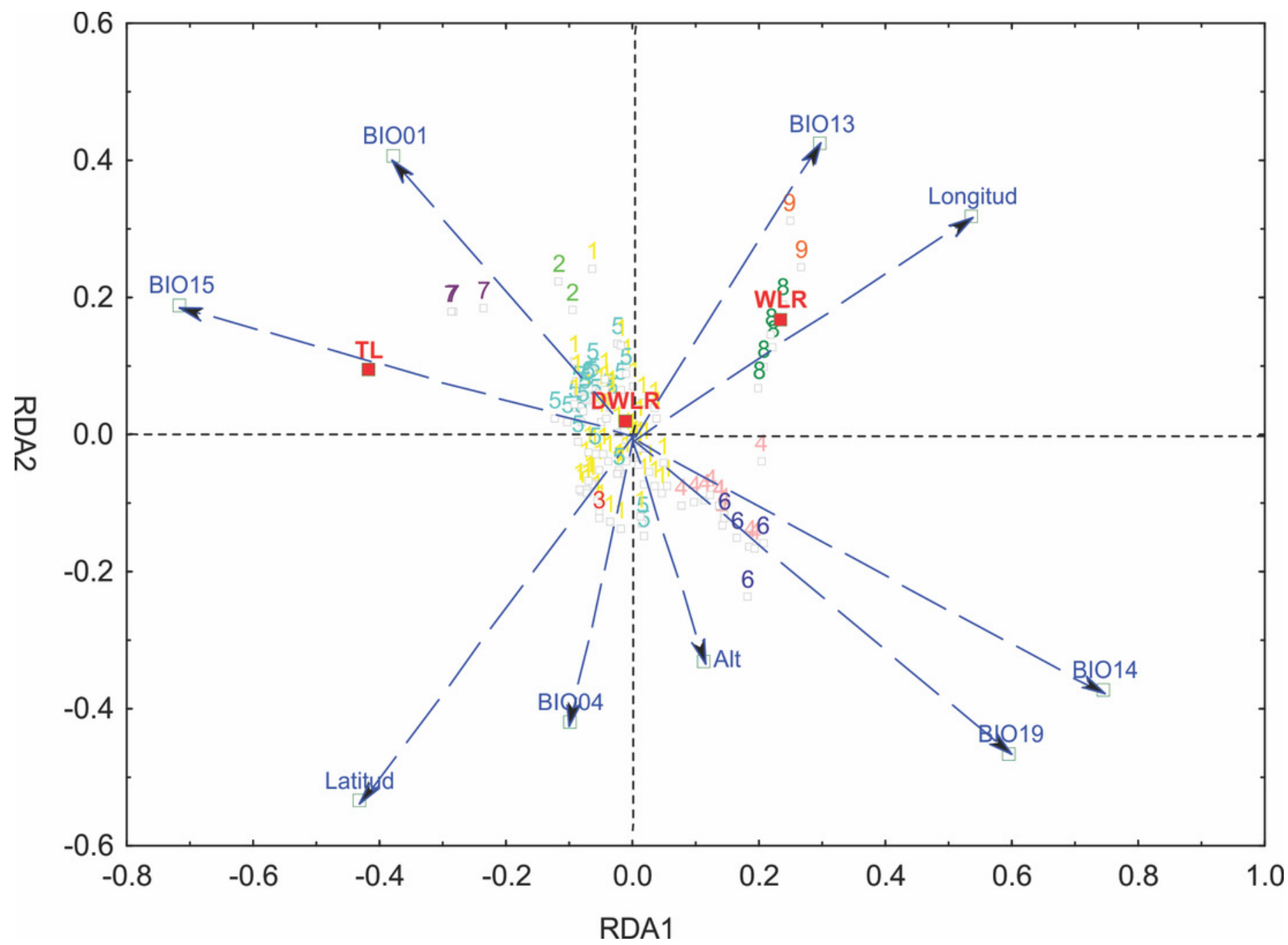




\section{Figure 7}

Correlations between total leaf length and bioclimatic variables

(A) Correlations between total leaf length ( $\mathrm{TL}$ ) and bioclimatic variables were positively correlated with annual mean temperature (BIO01) and (B) precipitation seasonality (BIO15) and (C) negatively correlated with precipitation of the driest month (BIO14), (D) precipitation of the wettest month (BIO13) and (E) precipitation of the coldest quarter (BIO19). 

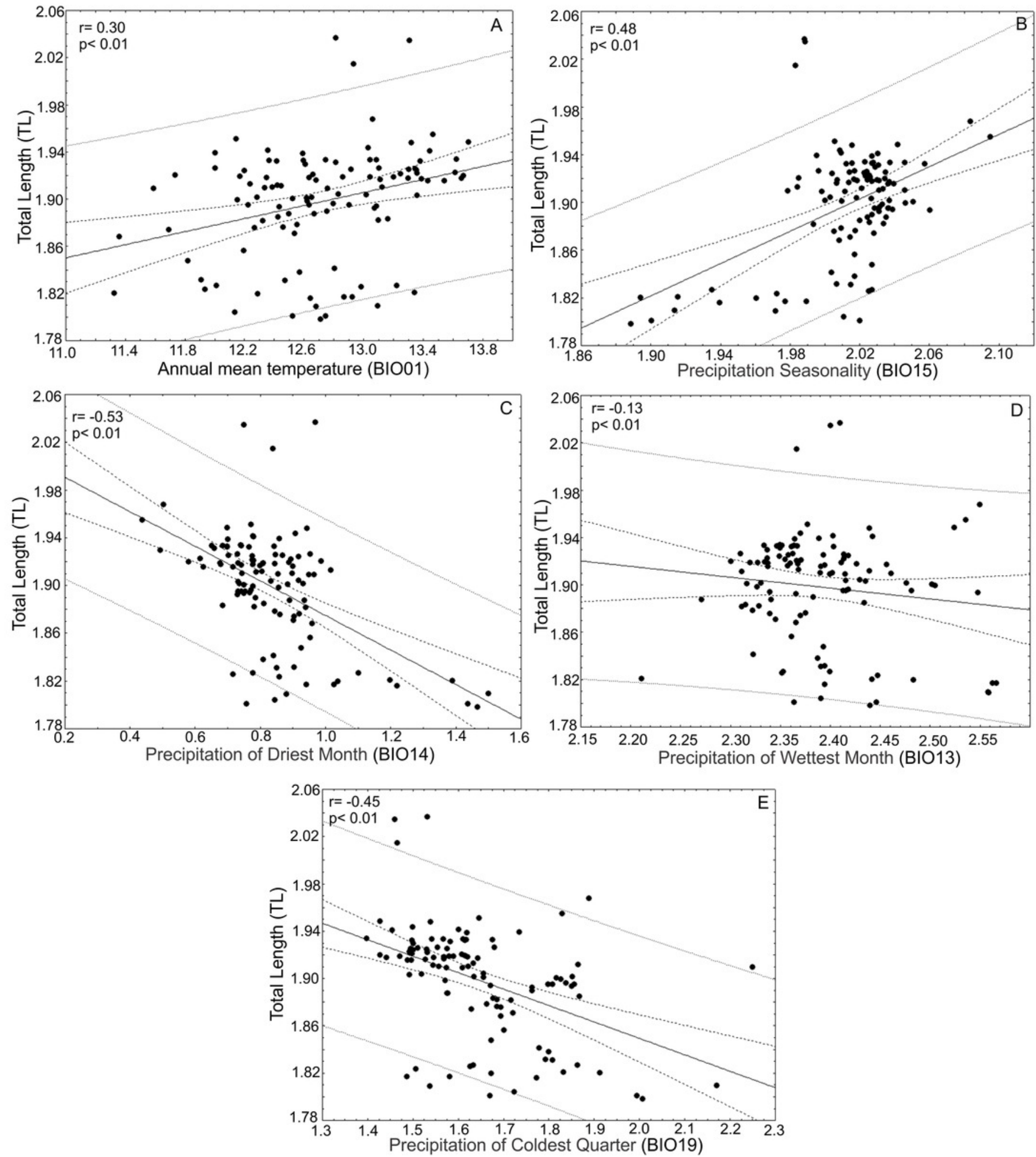


\section{Figure 8}

Correlations of the ratio between maximum width of the lamina/leaf length (WRL) and bioclimatic variables

The ratio between maximum width of the lamina (MW) and leaf length (LL) (WRL) as descriptor of leaf shape was (A) positively correlated with precipitation of the wettest month (BIO13) and (B) precipitation of the driest month (BIO14) and (C) negatively correlated with temperature seasonality (BIO04) and (D) precipitation seasonality (BIO15).
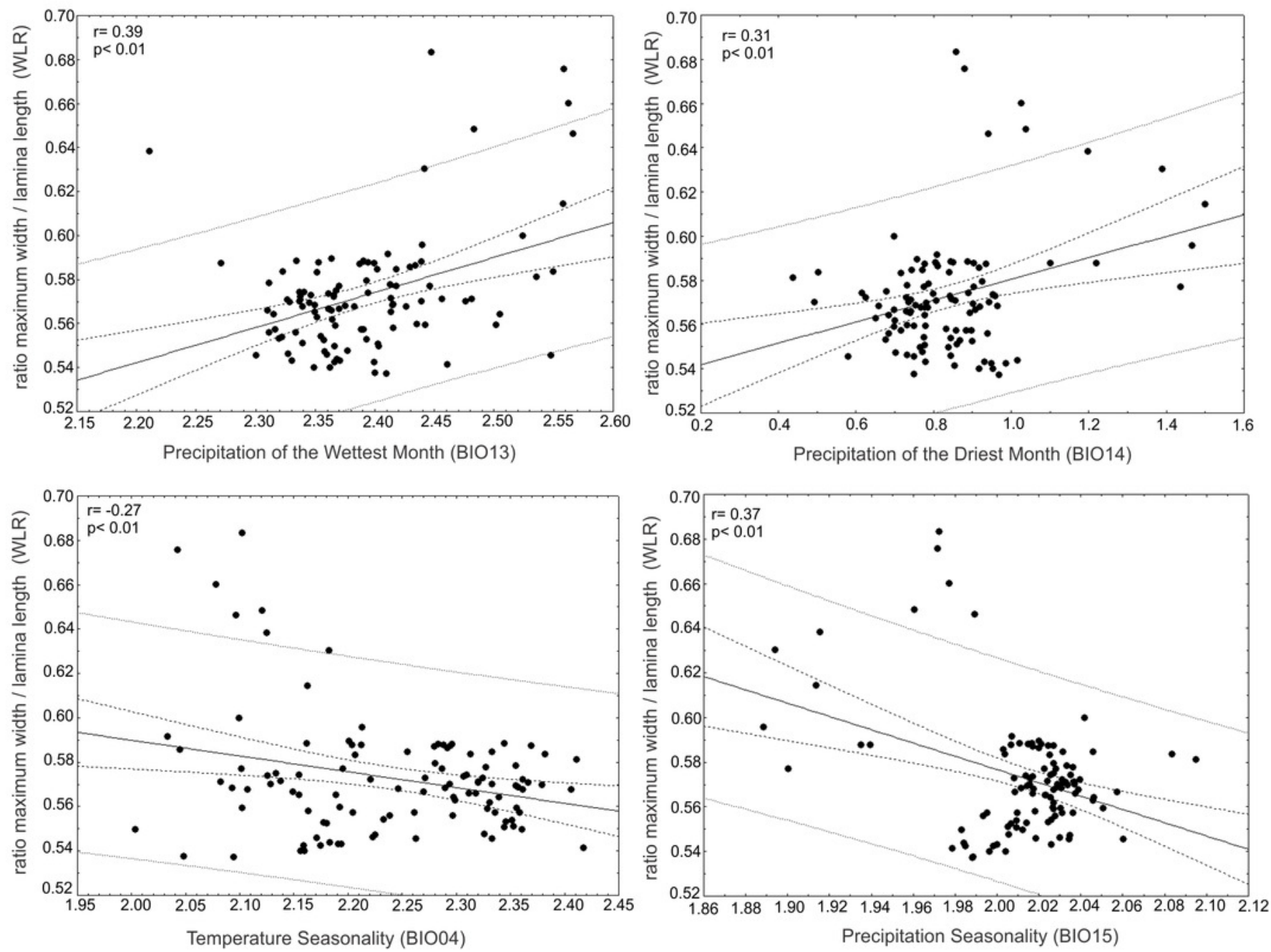


\section{Figure 9}

Correlations between the ratio between the distance from the base to the maximum width of the lamina/ leaf length (DWLR) and bioclimatic variables

The ratio between the distance from the base to the maximum width of the lamina (DW) and leaf length (LL) (DWLR) was (A) positively correlated with temperature seasonality (BIO04) and (B) precipitation seasonality (BIO15) and (C) negatively correlated with precipitation of the wettest month (BIO13), (D) precipitation of the driest month (BIO14) and (E) precipitation of the driest quarter. 

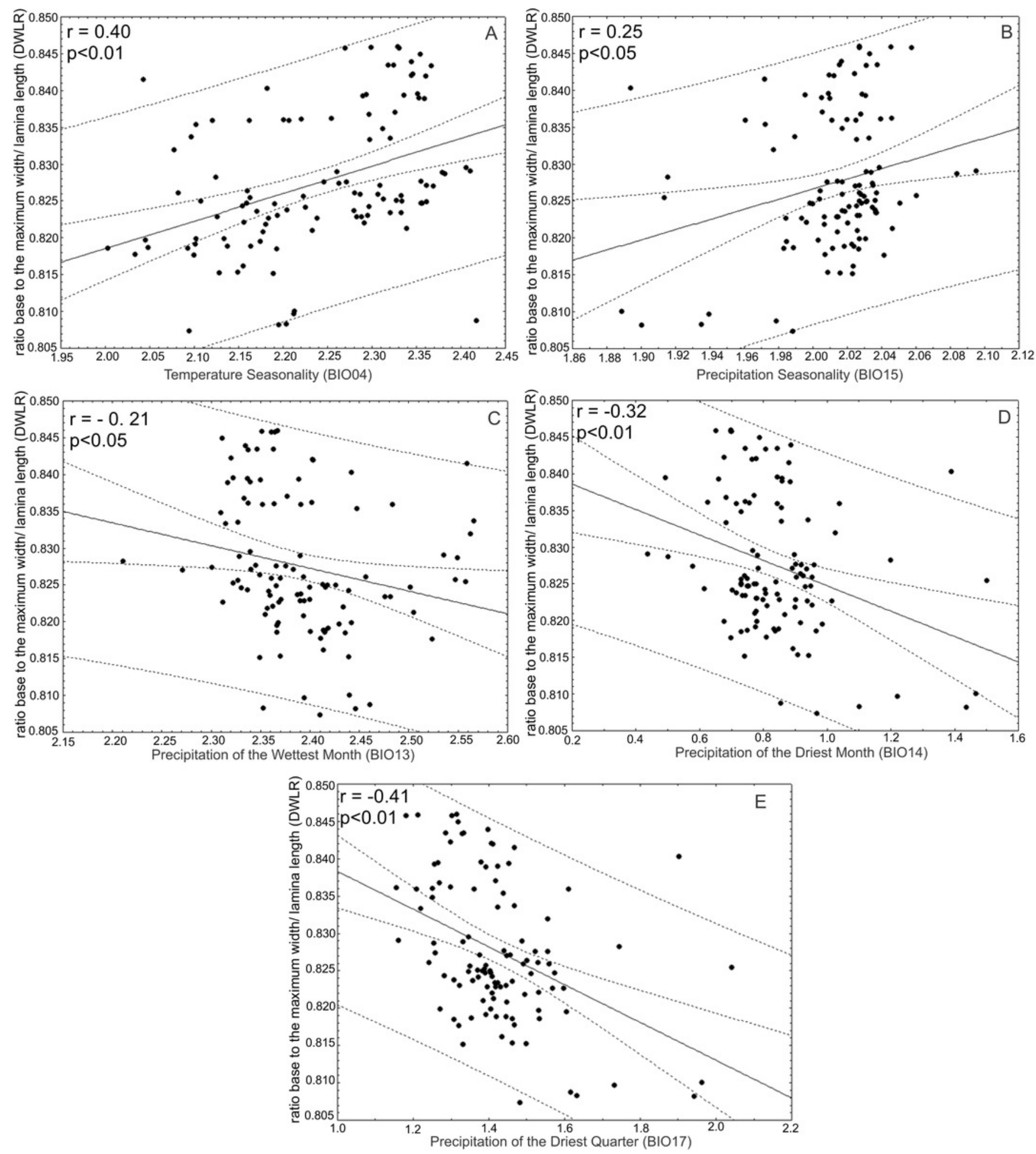


\section{Figure 10}

Correlations between morphological variables and latitude and/or longitude.

( $A$ and $B$ ) TL and DWLR were positively correlated with latitude and ( $C$ and $D)$ negatively correlated with longitude, (E) WLR was negatively correlated with latitude and (F) positively correlated with longitude. 

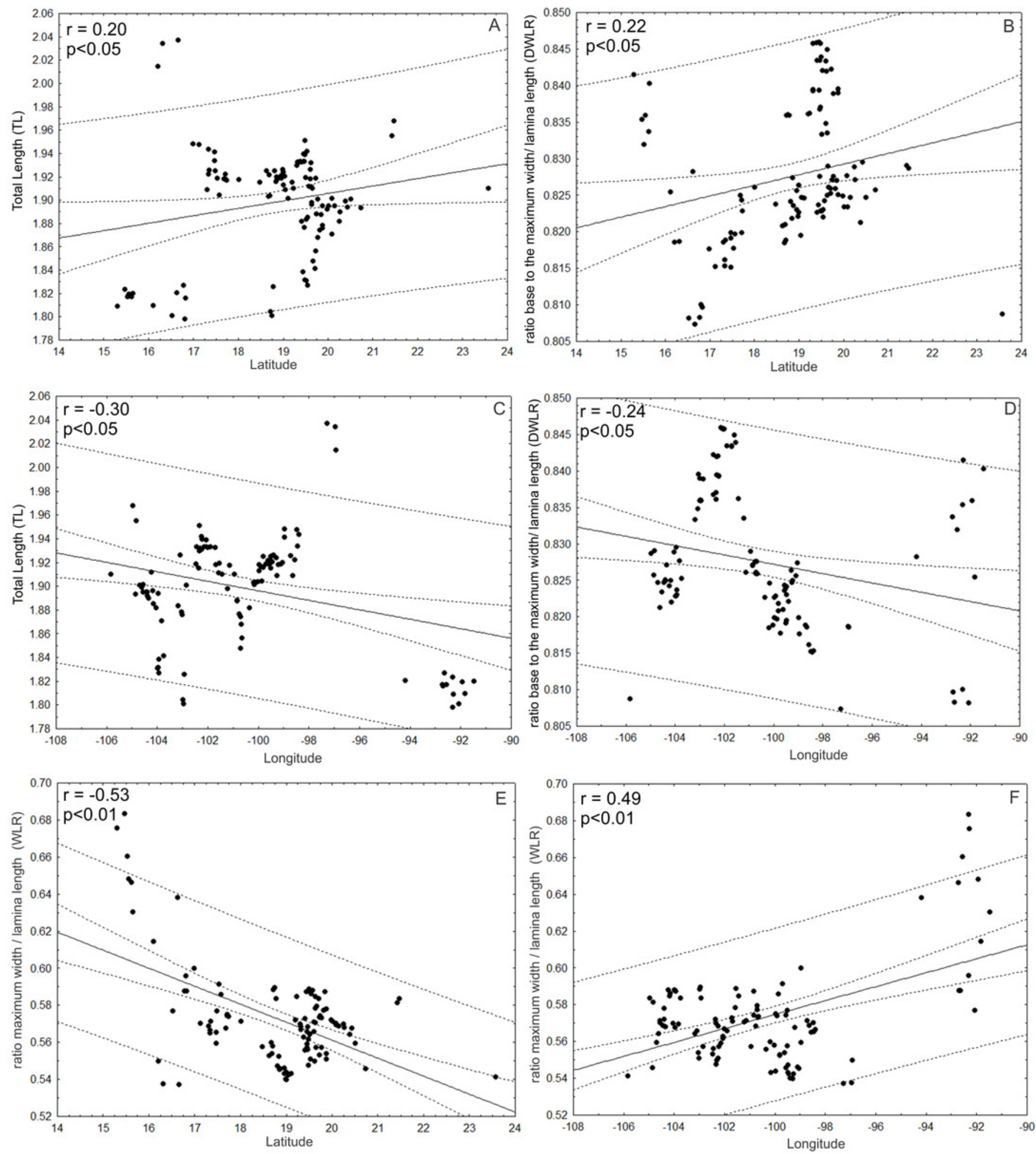